\title{
Mundos mesclados, espaços segregados: cultura material, mestiçagem e segmentação no sítio Aldeia em Santarém (PA)
}

\author{
Luís Claudio Pereira Symanski ${ }^{1}$ \\ Denise Maria Cavalcante Gomes ${ }^{2}$
}

RESUMO: Com base na análise da cultura material proveniente de unidades domésticas do núcleo urbano de Santarém (PA), ocupadas nos séculos XVIII e XIX, o presente artigo discute os processos de trocas culturais entre portugueses, luso-brasileiros, indígenas e mestiços. Embora esses grupos sociais tenham manipulado a cultura material visando expressar diferentes valores, relacionados à hierarquia, segmentação social e afirmação de identidades, a ambigüidade é uma característica das amostras analisadas, informando sobre as misturas de práticas e de referenciais culturais que levaram à construção de uma sociedade mestiça. PALAVRAS-CHAVE: Cultura material. Identidades. Trocas culturais. Mestiçagem. Amazônia. Arqueologia de Santarém, PA.

ABSTRACT: This article discusses the processes of cultural exchange between Portuguese, Portuguese-Brazilian, Amerindians, and mestizos based on the analysis of the material culture from households of Santarém (PA), occupied during the eighteenth and nineteenth centuries, . Although these social groups manipulated material culture aiming to express different values, related to hierarchy, social segmentation, and affirmation of identities, ambiguity also characterizes these assemblages. This material ambiguity informs about the mixtures of both practices and cultural references that brought about the building of a mestizo society.

KEYWORDS: Material culture. Identities. Cultural exchanges. Mestizage. Amazon. Santarém Archaeology.

Introdução

A atual cidade de Santarém, no estado do Pará, foi construída sobre uma aldeia indígena onde, segundo as fontes etno-históricas, teriam habitado os
1. Docente do Departamento de Sociologia e Antropologia, Faculdade de Filosofia e Ciências Humanas, Universidade Federal de Minas Gerais (UFMG). E-mail: <symanski@cnpq.br>

2. Docente do Departamento de Antropologia, Museu Nacional, Universidade Federal do Rio de Janeiro (UFRJ) E-mail:<denisecavalcante@ yahoo.com $>$.

As escavações realizadas por Denise Maria Cavalcante Gomes no sítio Aldeia, em Santarém, PA foram conduzidas como parte de um projeto de Pós-Doutorado junto ao Museu Nacional - UFRJ, sob a supervisão do Prof. Dr. Eduardo Viveiros de Castro, com o financiamento do CNPq (Processos: 151577/ 2005-6 e 473224/ 2006-2) entre os anos 2006 e 2008. Trabalhos subseqüentes em 2010 foram financiados por meio de um auxílio à pesquisa concedido pela Fapesp (Processo: 2008/58701-6) e em 2011, no Campus Tapajós, com o apoio da UFOPA. Os autores aradecem, ainda, às boas sugestões e críticas de um revisor anônimo. 
3. Ver Nimuendaju (1948, p. 2004).

4.Ver Roosevelt $(1991,1992)$.
Tapajó, grupo proto-histórico, dado como extinto no século XVIII, que ocupou uma ampla área do baixo Amazonas ${ }^{3}$. Esta ocupação Tapajônica pré-colonial tardia vem sendo associada ao processo de emergência de formações sociais complexas na Amazônia. Roosevelt ${ }^{4}$ enfatizou o impacto deletério que a conquista européia teve sobre estas sociedades amazônicas nos séculos XVI e XVII apontando os processos drásticos de redução demográfica causados por epidemias e as formas de destruição cultural provocadas por práticas de substituição de contingentes étnicos, tais como os descimentos promovidos pelos missionários e a escravidão forçada. Contudo, os contatos culturais envolvendo europeus e indígenas ocorridos nesta área, entre os séculos XVIII e XIX, não foram objeto de estudos anteriores por parte da arqueologia. $\bigcirc$ presente artigo analisa estas relações a partir da cultura material destes segmentos e das informações históricas disponíveis.

$\bigcirc$ processo de desenvolvimento urbano de Santarém ocorreu a partir de 1661, com o estabelecimento, no local, de uma missão jesuíta, a qual incorporou índios provenientes de diferentes regiões da Amazônia. Em 1697 foi construída uma fortaleza a leste da missão, com o objetivo de assegurar a presença portuguesa na Amazônia. Entre os séculos XVIII e XIX a cidade se conformou com a presença de dois núcleos populacionais distintos, um português e outro indígena, espacialmente segregados.

Pesquisas arqueológicas visando o estudo do componente pré-colonial na cidade de Santarém, PA, a partir de intervenções realizadas em quintais de residências, estabelecimentos comerciais, jardins e terrenos baldios, acabaram evidenciando também a cultura material referente ao processo de colonização e de consolidação do assentamento urbano, entre os séculos XVIII e XIX. Essas amostras revelam conjuntos tecnológicos diversificados, abrangendo desde objetos de produção artesanal local a artefatos importados. Este material é informativo das práticas dos principais grupos sociais que conformaram essa sociedade: portugueses, luso-brasileiros, indígenas e mestiços.

Neste artigo, além de discutirmos os processos de formação do sítio Aldeia e algumas práticas de deposição de refugo, a cultura material do período histórico é analisada, visando discutir questões relacionadas aos processos de trocas culturais entre os componentes dessa sociedade. Esses processos envolveram tanto segmentação, hierarquia e afirmação de identidades, quanto misturas e hibridização.

A formação histórica de Santarém

As primeiras referências sobre a localização geral e a grande extensão da aldeia dos Tapajó, situada na confluência do rio homônimo com o Amazonas, datam do século XVI e provém da crônica de Carvajal (1941), que entre 1540 e 1542 acompanhou a viagem do espanhol Francisco de Orellana, responsável pelo primeiro descobrimento do rio das Amazonas. De acordo com o estabelecido 
pelo Tratado de Tordesilhas, grande parte da Amazônia correspondia à Espanha. Com a união das coroas ibéricas, em 1580, este tratado perdeu sua força, abrindo espaço para sucessivas incursões portuguesas na região. $\bigcirc$ século XVII se consolidou como a época da expansão portuguesa na Amazônia, visando à defesa e posse do território por meio da construção de fortificações, expulsão de outros grupos europeus, organização de viagens de reconhecimento e da atividade missionária ${ }^{5}$.

Em 1637 a expedição de Pedro Teixeira partiu do Pará em direção a Quito visando garantir a ocupação da Amazônia portuguesa e a conquista do oeste. Sua passagem pela região de Santarém, durante a viagem de volta ao Pará, em 1639, foi descrita por Acuñab, estando associada ao aprisionamento de índios Tapajó. Nesta mesma época Heriarte”, que também participou da expedição de Pedro Teixeira, reconheceu a aldeia dos Tapajó como a maior da região, enfatizando a existência de um elevado contingente populacional nos arredores, reportando uma cifra possivelmente exagerada (sessenta mil guerreiros), contudo ameaçado pela escravidão indígena promovida pelos portugueses. Para Porro ${ }^{8}$, o episódio de aprisionamento dos Tapajó deve ser compreendido num contexto econômico que buscava substituir os escravos africanos, inacessíveis aos moradores do Pará devido aos altos preços, pela mão de obra indígena. Segundo Oliveira 9 , os escravos indígenas na Amazônia trabalhavam em serviços públicos e domésticos, na construção de igrejas e casa, em roçados, nas atividades de coleta e também serviam de soldados e remadores nas tropas de conquista.

Em 1661 a aldeia dos Tapajó foi transformada na sede da primeira missão jesuíta do rio Amazonas, pelo padre João Felipe Betendorf, seguindo as recomendações da Companhia de Jesus. Foi assim construída uma igreja, refletindo os propósitos de conversão religiosa, mas também de cunho político, tendo em vista o processo de ocupação territorial ${ }^{10}$.

A missão jesuíta em Santarém se constituiu num pequeno povoado em torno da igreja, tendo recebido, no decorrer dos anos, diversas populações indígenas oriundas dos deslocamentos promovidos pelos jesuítas ao longo do Amazonas e seus tributários. Esses descimentos alteraram de modo drástico a organização cultural e sócio-política desses grupos, resultando em configurações multiétnicas. $\bigcirc$ trabalho indígena, voltado para a coleta das "drogas do sertão" (cacau, baunilha, urucu, castanha, cravo e salsaparrilha), garantia o sustento da missão. Em 1697 foi iniciada a construção da Fortaleza do rio Tapajós, um dos importantes marcos defensivos da coroa portuguesa na Amazônia, situada numa colina a leste da cidade ${ }^{11}$. Betendorf se referiu à localização da aldeia e sua proximidade da fortaleza: "Tinha-me o Padre Superior ordenado que fizesse residência no outeiro onde hoje está a fortaleza e chegasse a aldea para o pé do monte; tudo se intentou e roçou-se o monte; deixadas as duas arvores que até o presente se vêm e chegou-se a aldea para elle..." ${ }^{12}$.

Durante a administração de Francisco Xavier de Mendonça Furtado, Governador do Estado do Maranhão e Grão-Pará, que pôs em prática a política pombalina na região, uma nova fase se iniciou, com a criação da Companhia
5.Ver Oliveira (1988, p. 73).

6. Ver Acuña (1941).

7.Ver Heriarte (1874)

8. Ver Porro (1996).

9. Ver Oliveira (1988)

10.Ver Gomes (2002, p. 155).

11. Ver Fonseca (2006).

12. Ver Betendorf (1909, p. 470). 
13.Ver Oliveira (1988,p.83-88).

14. Ver Fonseca (2006)

15.Ver Daniel (2004, p. 397).

Geral do Comércio do Grão Pará e Maranhão (1755), destinada a fomentar a comercialização dos produtos provenientes do extrativismo amazônico na Europa. Nesta época também foi introduzida na Amazônia a mão de obra escrava africana. Com a criação do Diretório dos Índios em 1757, que retirava o poder dos missionários de administrar as aldeias, teve início uma fase que culminou com a expulsão dos jesuítas de Portugal e seus domínios, em 1759. Pombal proíbiu a escravidão indígena, transformou as aldeias em vilas e criou uma legislação que estimulava o casamento entre brancos e índios, tendo por objetivo a integração dos índios à civilização ${ }^{13}$.

Esta conjuntura teve influência no crescimento da vila de Santarém e em sua configuração social. Porém, mesmo com o incentivo oficial à miscigenação, os remanescentes da aldeia indígena foram mantidos espacialmente segregados dos colonizadores ${ }^{14}$. Em meados do século XVIII o Padre João Daniel, que viveu entre os Tapajó no período de 1741 a 1757, descreveu, na vila de Santarém, a existência de dois núcleos populacionais distintos, formados por portugueses e indígenas (Figura 1). Seus registros, contudo, indicam que a aldeia não mais estava situada junto ao morro da fortaleza, mas logo após o núcleo dos portugueses, local que corresponde ao atual bairro de Aldeia:

"O rio Tapajós tem na sua foz uma fortaleza sobre o rio Amazonas, e é a segunda da parte do sul. Está eminente em um recanto sobre uma rocha viva com seu presídio, como as mais; a ela aportam todas as embarcações (...). Tem uma povoação pequena de portugueses, tem também quase imediała uma povoação de índios, intitulada antes a missão de Tapajós e hoje batizada de vila de Santarém. É bastante numerosa, bem arruada e sadia, com boa igreja, que também serve de paróquia aos portugueses da povoação imediata, e presídio da fortaleza, posto que também tem sua capela, pequena, mas linda"15.

Esta localização da aldeia indígena foi mantida no século XIX, período em que vários autores confirmaram a divisão de Santarém em duas partes distintas,

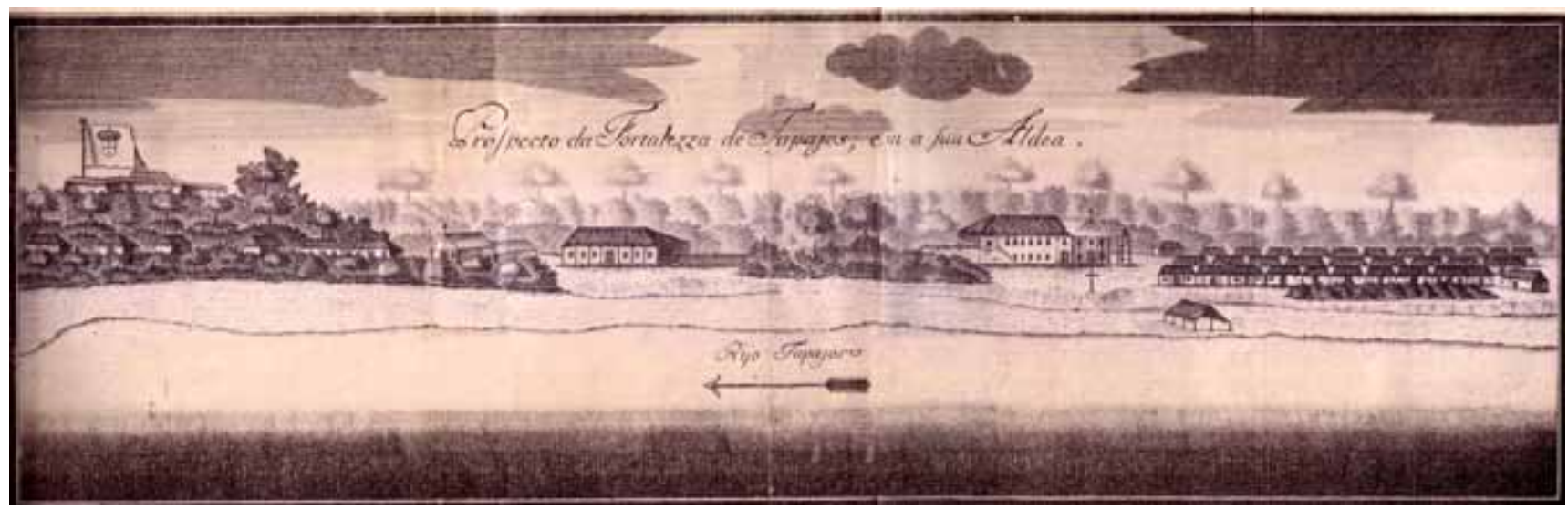

Figura 1 - Gravura de Santarém feita por Schwebel em 1756, indicando a fortaleza, o núcleo português e a aldeia. 
a cidade propriamente dita, situada desde o morro da fortaleza até a igreja matriz

e seus arredores, e a aldeia indígena, já bastante modificada, que se estendia para oeste. Em 1761 foi iniciada a construção da igreja matriz, situada a pouco mais de 200 m a leste da igreja da missão original, que hoje corresponde à catedral de Nossa Senhora da Conceição (Figura 2). Somente a partir de 1853 é que a cidade começou a se expandir a leste, após o morro da fortaleza, com a construção da Câmara Municipal na Praça da Municipalidade, atual Praça Barão de Santarém. Nesta época, existiam apenas seis ruas e nove travessas, sendo que a aldeia já começava a ser invadida por brancos ${ }^{16}$.

Spix e Martius ${ }^{17}$, naturalistas que passaram por Santarém em 1819 , forneceram várias informações sobre a composição populacional da vila e as formas peculiares de inserção do colono no comércio regional. Segundo estes, o número de habitantes registrados nas listas da igreja não ia muito além de 2.000,

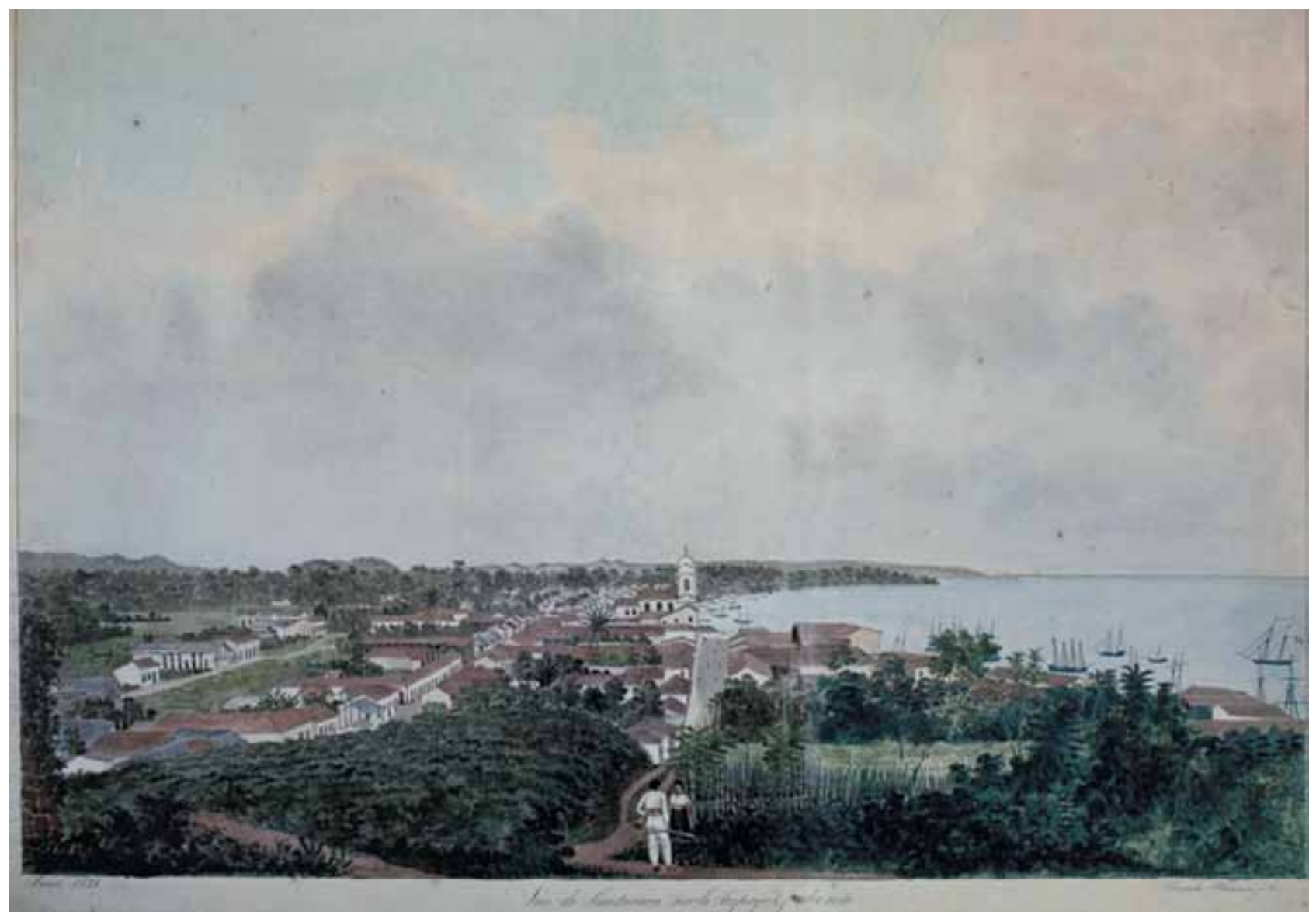

Figura 2 - "Vue de Santarém sur le Tapajós, prise du cote de l'ovest". Aquarela de a de Santarém feita por Hercule Florence em 1828, observando-se, ao fundo, a igreja matriz e a aldeia indígena a oeste. Fonte: Florence (1988). 
18. Idem, p.99.

19. Ver Florence (1977, não paginado)

20. Idem. contando todos os que viviam dispersos, além de fazendeiros que moravam longe e as inúmeras famílias de índios que para eles trabalhavam, calculando com isto um total de 4.000 habitantes em todo o distrito, ocupando uma área de 15 léguas quadradas. Dentre os moradores, destacavam os brancos mais numerosos, alguns deles casados com mulheres indígenas. Os autores apontam que os portugueses pertencentes às classes mais baixas foram estimulados a emigrar para estas partes do Brasil, onde as relações com os índios e a facilidade de empregálos nas plantações, em lugar dos escravos, consistia numa vantagem. Este trato com os índios, cujos serviços e os artigos que traziam ao mercado não se pagavam com dinheiro fez com que muitos colonos montassem lojas com toda espécie de mercadorias européias, dando assim à vila uma aparência de animado comércio. Santarém consistia no principal empório de comércio entre a parte ocidental da província do Pará e a capital ${ }^{18}$.

Hércule Florence, que visitou Santarém em 1828 assim descreveu o núcleo urbano em formação:

"Bela cidade é Santarém, situada na confluência do Tapajós com o Amazonas. Localiza-se à margem oriental do primeiro desses rios, em terreno plano, com suave inclinação para a água. Num outeirozinho a leste, ainda se vêem as ruínas de um fortim... A região em torno é plana, exclusive a 3 léguas em direção ao sul, onde se avistam montanhas, as primeiras que notamos desde Itaituba. Largas, alinhadas a cordel e em ângulos retos são as ruas de Santarém. A melhor igreja que vi a partir de São Paulo é a local erguida no centro do largo. Um frontão de duas torres salientam sua fachada. Santarém possui seu aldeamento de índios, como quase todas as localidades da província. Situa-se ele, aqui, do lado ocidental, em um grande terreno, tendo em derredor umas poucas casas, separa-o da parte mais povoada com características urbanas. Não pude, antes, passar por esse terreno, em que os acentos fechados do idioma português se fazem substituir pelas moles e incompletas articulações da Língua Geral Brasileira. Os habitantes do amontoado de choças que compõem a aldeia indígena falam a linguagem de seus pais, outrora reunidos pelos jesuítas, que fundaram o povoado sob o nome de Tapajós, também usado pela cidade, este trocado pelo de Santarém, sem dúvida por efeito da influência exercida no sentido de se darem nomes de cidades portuguesas a todas as do Amazonas"19.

Florence também se referiu à composição da população de Santarém:

"Cinco classes distintas se notam na população de oito a dez mil almas de Santarém: brancos, índios, mamelucos, mulatos e negros. Entre os primeiros a metade é filha da Europa, de modo que as paixões políticas são ainda muito veementes. Os índios são geralmente apelidados tapuios e menos cobreados que os das matas. Livres, por lei, o são de fato, graças mais às florestas do que pelo respeito que merecem de seus direitos. Dóceis e embora indolentes, são eles que fazem quase exclusivamente a navegação dos inúmeros rios da província do Pará (...). Na província do Pará, os negros e mulatos são em pequeno número, porque tendo logo em princípio sido os índios reduzidos à escravidão, tornou-se tarde e menos ativa do que em outros pontos do Brasil a introdução dos filhos da África"20.

Anais do Museu Paulista.v. 20.n.2. jul.-dez. 2012. 

à segunda metade do século XIX. Bates chegou em companhia do famoso naturalista Alfred Wallace em 1848 e fixou residência em Santarém entre 1851 e 1854. O autor descreveu Santarém como o centro mais civilizado e importante desde o Peru até o Atlântico. Contraditoriamente, aponta que em todo o distrito não existiam mais do que 6500 habitantes e que atrás da cidade e para o interior era totalmente desabitado, sendo que os jaguares rondavam à noite perto das esquinas das ruas suburbanas. Segundo ele, toda a produção de cacau, peixe salgado e outros artigos de uma enorme área passavam pelas mãos dos negociantes de Santarém, que também comercializavam a salsaparrilha, a copaíba, a borracha a farinha e outros produtos com os índios da região.

Em meados de 1870, o Tenente da Armada Imperial Rufino Luis Tavares $^{21}$ descreveu a cidade de Santarém como a mais populosa e comercial da província do Pará, funcionando como entreposto de comércio desde o Alto Tapajós até Alenquer. De Belém chegavam as fazendas, ferragens, quinquilharias e bebidas procedentes da Europa e da América do Norte, enquanto de Santarém partia a borracha, o cacau, o peixe, a carne, o couro, a salsaparrilha, castanhas, óleo de copaíba, cravo e algumas cabeças de gado. De acordo com Tavares, nesta época existiam 300 casas em Santarém, sendo as mais modernas assobradadas. Dentre as principais estava o palacete do Barão de Santarém, existente até hoje, cuja fachada imitava a do palácio do governo da província do Pará. A população de Santarém nesta época era composta por 2304 indivíduos, sendo 1837 livres e 467 escravos $^{22}$.

Portanto, mais do que um mero reflexo do contexto sócio-político da região amazônica, a formação histórica de Santarém se fez a partir de certos estímulos. De simples aldeamento missionário do século XVII, cuja presença indígena era majoritária, passou a constituir uma aprazível vila colonial no século XVIII, organizada em torno da igreja de Nossa Senhora da Conceição. Tardiamente alguns escravos negros foram adquiridos, diversificando a feição étnica da região. No século XIX, a cidade recebeu um maior afluxo de portugueses, que se dedicaram ao comércio e mantiveram fazendas de gado e de cacau, além de seringais nas imediações. Esta classe de comerciantes e fazendeiros, que impressionou os viajantes da época, morava em sobrados da cidade e desenvolvia atividades produtivas inicialmente a partir do trabalho indígena baseado na troca de mercadorias, bem como numa rede de favores e obrigações, tendo sido posteriormente acrescido da mão de obra escravizada de origem africana. Se as fontes documentais apresentam informações exíguas sobre o modo de vida da população de Santarém, o estudo da cultura material pode trazer subsídios importantes que permitem compreender a inserção desta região no cenário nacional. 
23. Ver Cusick (1988).

24. Idem, p. 131.

25. Ver, por exemplo, Wheaton e Garrow (1985), Brochado (1974), para o caso dos Guarani.

26. Ver Stein (2005, p. 28).

27.Ver Delle (2000), Ferguson (1992)e Singleton (1998).

28. Ver Delle (2000).
Encontros culturais, identidades e cultura material

Santarém, portanto, foi palco de encontros culturais desde praticamente o início do processo colonizador europeu. Nos séculos XVI e XVII esses encontros promoveram etnocídio, realocações forçadas de populações indígenas e etnogênese. Começaram, assim, a ser conformadas novas configurações culturais, produto das trocas entre portugueses, luso-brasileiros, indígenas, mestiços, e, em uma menor escala, africanos. As identidades que emergiram deste processo foram múltiplas, não podendo simplesmente ser reduzidas à dicotomia colonizadorcolonizado.

Na arqueologia histórica a temática dos encontros culturais foi abordada, durante muito tempo, com base no modelo tradicional de aculturação desenvolvido pela antropologia culturalista norte-americana durante a primeira metade do século XX23. Este modelo era pautado em uma visão de culturas como entidades circunscritas, caracterizadas por um conjunto de feições específicas, que se estendiam da tecnologia à cosmologia, denominadas de traços culturais. Os estudos desenvolvidos sob essa perspectiva apresentavam uma série de características comuns, tais como a listagem dos traços culturais que foram transferidos entre as sociedades, a visão de culturas como entidades bem delimitadas, a minimização da agência humana, a identificação dos mecanismos de filtragem que explicariam a incorporação seletiva de traços da cultura forânea, e a omissão das relações de poder, com a tendência a considerar as sociedades simples como passivamente incorporando os traços da cultura dominante ${ }^{24}$. Nos estudos arqueológicos este processo era averiguado através da substituição gradual da cultura material nativa por aquela dos colonizadores ${ }^{25}$. As falhas deste modelo são óbvias, e dizem respeito, antes de tudo, à igualização de artefatos com culturas, de modo que mudanças nestes equivaleriam diretamente a mudanças naquelas.

Nas últimas décadas, estudos em contextos de interação multicultural levaram a uma crescente percepção de que identidades compostas emergem como resultado das negociações entre a agência local e as estruturas coloniais ${ }^{26}$. $\mathrm{Na}$ arqueologia histórica foram os estudos em contextos de ocupação africana, sobretudo em plantations, que levaram os arqueólogos a buscar modelos que pudessem explicar a emergência de novas configurações culturais envolvendo, por um lado, a diversidade cultural africana presente na senzala, e, por outro, as trocas e influências mútuas entre esse grupo diversificado, os europeus e eurodescendentes, e as populações ameríndias. Começaram, assim, a ser aplicados os modelos correlatos de crioulização, transculturação e etnogênese ${ }^{27}$. Esses modelos focalizam-se no papel das trocas culturais entre grupos e sociedades distintas como vias de mão-dupla, considerando, assim, que os grupos eurodescendentes tendem a crioulizar-se tanto quanto afro-descendentes e indígenas ${ }^{28}$. Do mesmo modo, consideram que a simples incorporação da cultura material dos colonizadores pelos colonizados não é um indicativo da adoção passiva das 
feições culturais daqueles, dado que estes têm a habilidade de se reapropriar desses itens a partir de referenciais próprios, atribuindo-lhes usos e significados que podem ter pouca ou nenhuma identificação com aqueles originalmente atribuídos pelos colonizadores ${ }^{29}$.

Por outro lado, acadêmicos influenciados pela teoria pós-colonial consideram que o hibridismo que marca a emergência das identidades coloniais põe em cheque a própria concepção tradicional de cultura como uma entidade circunscrita, bem delimitada, condicionante dos comportamentos de seus portadores ${ }^{30}$. Segundo Gosden ${ }^{31}$, essa natureza híbrida das culturas coloniais denota que todos os participantes dessa configuração, tanto colonizadores quanto colonizados, acabam por ter alguma sorte de influência nas estruturas de poder, dominação e resistência dela resultante, complexificando, assim, dicotomias como colonizador/colonizados e dominante/dominado. Seguindo essa perspectiva, Gruzinski32 adota a noção de mestiçagem para se referir às misturas que ocorreram nas Américas, a partir do século XVI, entre seres humanos, imaginários e formas de vida, vindos de quatro continentes - América, Europa, África e Ásia. Segundo ele, este processo é tanto objetivo, observável em fontes variáveis, quanto subjetivo, relacionado à consciência que têm dele os atores do passado, consciência que pode se expressar "tanto nas manipulações a que eles se dedicam, como nas construções que elaboram ou nos discursos e condenações que formulam"33.

Deve ser, contudo, considerado que, embora este reconhecimento das configurações coloniais como produtos da agência de todos os indivíduos e grupos nelas envolvidos seja um avanço frente aos modelos teóricos que realçam somente a perspectiva dos grupos politicamente dominantes, tal posicionamento pode levar a um risco de se minimizar o impacto brutal do colonialismo sobre as populações nativas, subdimensionando o fato de que tais populações simplesmente não tiveram a escolha de evitar a conquista, mas foram, antes de tudo, vítimas de tal processo. Dentre as conseqüências deletérias desse processo nas Américas, Hill ${ }^{34}$ destaca os colapsos demográficos, as realocações forçadas, a escravidão, as epidemias e o recrutamento étnico. Portanto, as relações assimétricas de poder entre os agentes envolvidos nas situações de contato cultural devem ser consideradas em todas as instâncias. $\bigcirc$ papel da cultura material neste processo é determinante, como bem coloca Gosden ${ }^{35}$, posto que o poder emana dos centros coloniais muito mais através dos artefatos e das práticas a eles associadas do que pela superioridade econômica ou militar. Nos contextos coloniais esta cultura material desestabiliza os valores tradicionais, impactando todos aqueles envolvidos neste processo, tanto nativos quanto colonizadores.

Estas críticas ao modelo tradicional de aculturação e de cultura possuem grande valia para compreender contextos tais como o de formação histórica da cidade de Santarém. Após um período inicial de contatos coloniais baseados exclusivamente em práticas de dominação indígena, sobretudo durante os séculos XVI e XVII, uma outra fase pode ser identificada com o surgimento de uma nova configuração social em contexto urbano, marcada tanto por relações
29. Ver Ferguson (1992), Howson (1990) e Wilkie (2000).

30.Ver Gruzinski (2001,p.48).

31.Ver Gosden (1999,p. 243)

32. Ver Gruzinski (2001, p. 48-52).

33. Idem, p. 62.

34.Ver Hill (1988, p. 166).

35. Ver Gosden (2004, p. 3) 
36. Ver Gomes (2006, 2008, 2010).

37. Idem $(2006,2011)$.

38. Ver Quinn (2004), Roosevelt $(1999,2009)$.

39.Ver Gomez e Luiz (2011). de desigualdade e segregação sócio-cultural quanto por fusões. Durante os séculos XVIII e XIX portugueses, índios e mestiços dividiram os espaços da cidade. Partilharam de artigos importados que representam a inserção do capitalismo nesta área periférica, cuja variabilidade artefatual permite não apenas identificar diferenças culturais e sócio-econômicas mas também ambigüidades e misturas. Por outro lado, novos artefatos, onipresentes nos contextos em estudo, foram criados, produto de tecnologias nascidas desses encontros culturais. Se, de um lado, eles expressam escolhas tecnológicas, reapropriações, segregação e resistências, de outro também informam sobre convergências de práticas e de costumes, tendo atuado ativamente na construção de uma cultura mestiça nesta região da Amazônia.

As escavações e os processos formativos do sítio Aldeia

Gomes realizou as primeiras escavações sistemáticas, autorizadas pelo IPHAN, no sítio Aldeia, em Santarém, PA ${ }^{36}$. Estas foram conduzidas até o presente momento nos atuais bairros do Centro, Santa Clara e Aldeia, em áreas escolhidas a partir do trabalho anterior de delimitação deste sítio, que estabeleceu uma malha de tradagens arqueológicas aproveitando o traçado urbano. As tradagens tiveram início no morro da antiga Fortaleza, tendo prosseguido $4 \mathrm{~km}$ em direção oeste até o bairro de Mapiri, que termina na confluência do lgarapé de mesmo nome com o rio Amazonas. Os resultados revelaram um extenso e contínuo sítio de terra preta arqueológica, de formato linear, medindo $4 \mathrm{~km} \times 0,7 \mathrm{~km}$. Este se inicia logo após o morro da Fortaleza, no atual bairro do Centro e continua por $2 \mathrm{~km}$ até o fim dos bairros de Aldeia e Fátima. A partir daí há uma interrupção do sítio no bairro de Laguinho, referida por Bates. Esta área foi descrita pelo mesmo autor, no século XIX, como uma região ocupada por lagos.

Segundo informações orais e de acordo com intervenções arqueológicas realizadas por $\mathrm{Gomes}^{37}$ os vestígios ressurgem no bairro da Liberdade e em seguida no bairro de Salé que corresponde ao atual "Sítio do Porto", escavado por Roosevelt e associados ${ }^{38}$ e também por Gomes em 2011 , nas dependências do Campus Tapajós, na UFOPA ${ }^{39}$. Neste caso consideramos o sítio Aldeia como esta unidade contínua que compreende os bairros do Centro, Santa Clara, Aldeia, Fátima, Laguinho e Liberdade que pode ser visualizada no mapa (Figura 3), cujo conteúdo do pacote arqueológico, embora predominantemente pré-colonial, apresentou áreas com vestígios de ocupação histórica.

Os objetivos da pesquisa realizada nos anos de 2008 e 2010 estiveram voltados para a análise dos processos formativos do sítio Aldeia, especialmente a compreensão dos contextos cerimoniais relacionados à cerâmica de estilo Tapajó. Desse modo, as escavações ocorreram em locais que apresentaram indícios de ocupação pré-colonial e não necessariamente em áreas 


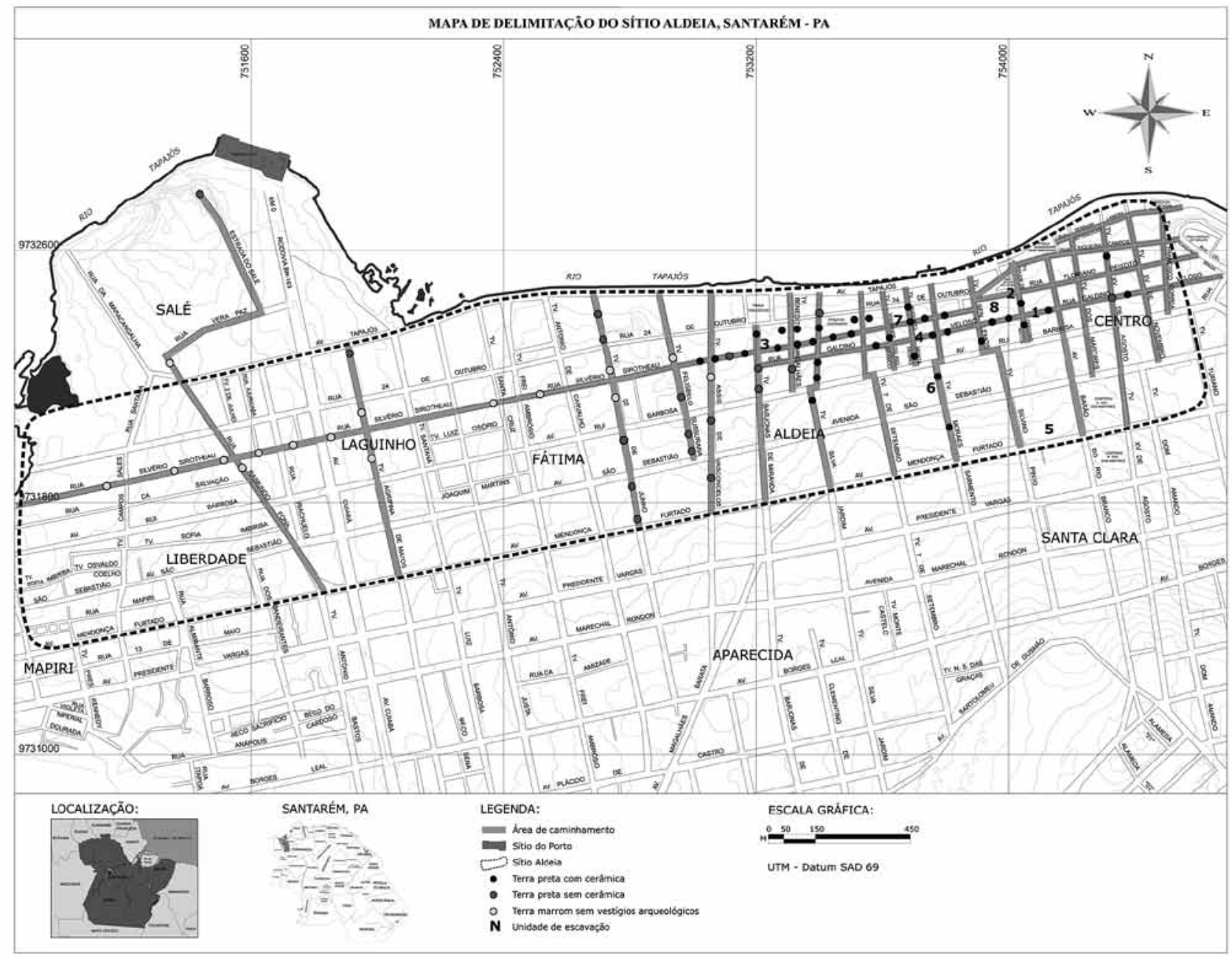

Figura 3 - Mapa do sítio Aldeia, com indicação das intervenções realizadas e com a localização das unidades trabalhadas contendo material histórico.

onde a presença histórica era conhecida. Foram escavadas oito unidades de 2 X $2 \mathrm{~m}$, totalizando $32 \mathrm{~m}^{2}$ de escavações, cuja profundidade variou entre $1 \mathrm{~m}$ e $2,50 \mathrm{~m}$. Tais escavações ocorreram em terrenos particulares, sendo quatro em quintais de residências atuais, duas em terrenos baldios e duas em estabelecimentos comerciais.

De modo geral, as unidades apresentaram dificuldades de escavação relativas à intensa camada de entulho e material construtivo que precedia as camadas arqueológicas, tendo esta entre $30 \mathrm{~cm}$ e $50 \mathrm{~cm}$. Contudo, a principal característica observada foi a existência de densa ocupação histórica, com fragmentos de louças, vidro, ferro e cerâmica. Consideramos que este material seja proveniente de contextos domésticos, relacionados à estruturas específicas de habitação dos séculos XVIII e XIX e não a lixeiras coletivas, nem tão pouco 
provenientes de aterros. Em alguns casos, os artefatos estão reunidos e dispostos em estruturas cavadas pelos antigos ocupantes para acomodar o lixo (Figura 4).

Nas três unidades escavadas no bairro do Centro se observa uma baixa densidade de artefatos pré-coloniais na matriz de terra preta, com o predomínio de artefatos históricos - louças, cerâmica histórica, vidro e ferro. Enquanto na unidade 1 a camada histórica é mais sutil indicando o descarte aleatório, a escavação da unidade 2 foi marcada pela percepção nítida da existência de estruturas intencionalmente cavadas para deposição de vestígios, visíveis nos perfis. Novamente a presença de fragmentos de louças, frascos de remédios, vinho do Porto, cerâmica histórica acordelada e cerâmica torneada definem a intensidade da ocupação do século XIX. Apesar da predominância da ocupação histórica nesta unidade, foi possível isolar manchas de terra preta com fragmentos cerâmicos pré-coloniais. A unidade 3 apresentou apenas material histórico do século XX.

A unidade 4 foi aberta no quintal de uma residência, no limite dos bairros Centro e Aldeia. Nesta unidade também foi observada a existência de

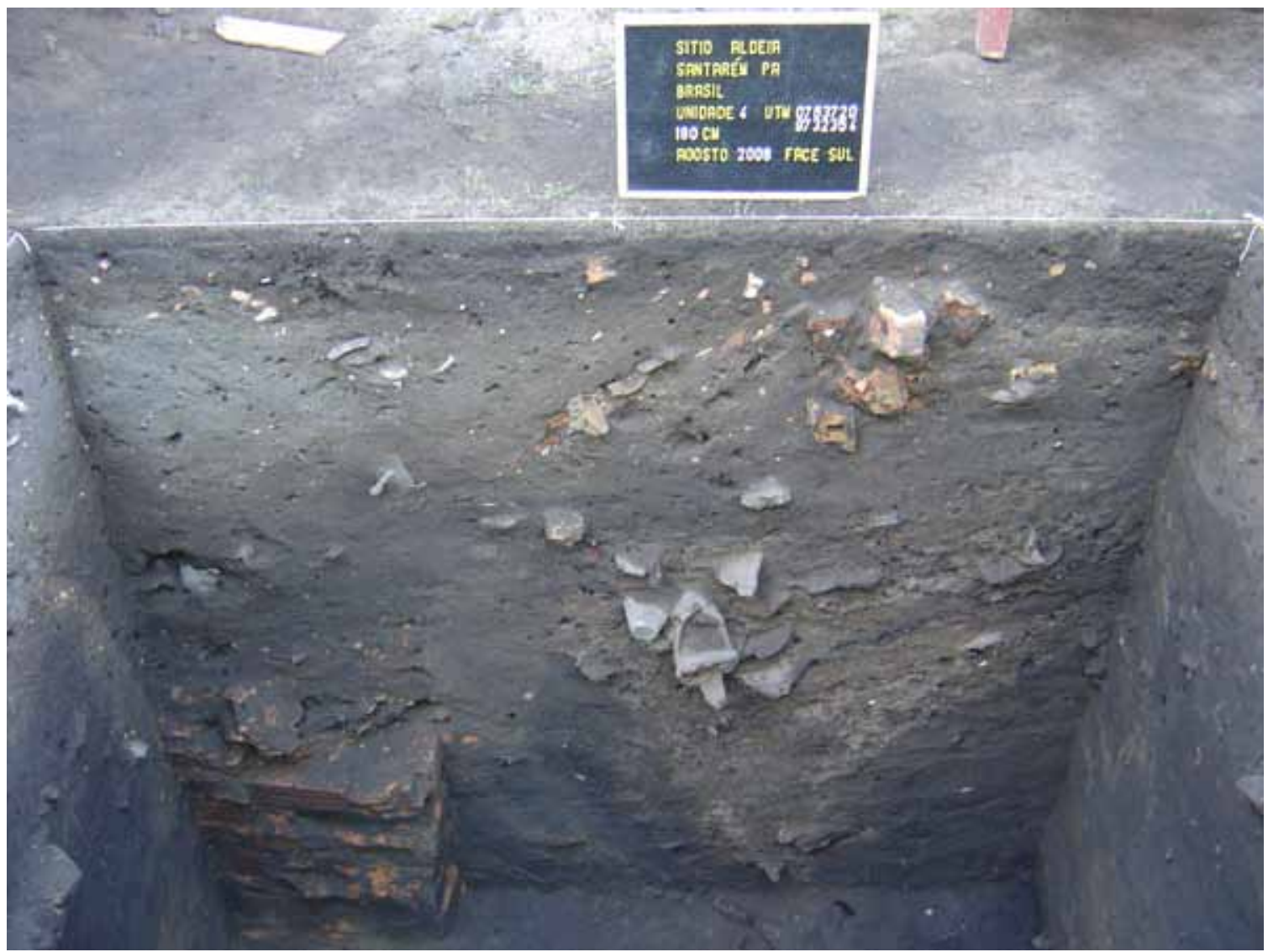

Figura 4 - Foto do Perfil Face Sul da Unidade 4 de escavação do sítio Aldeia, Santarém, PA, mostrando a existência de bolsões históricos intrusivos. Fotografia: Denise Maria Cavalcante Gomes. 
estruturas cavadas, sob a forma de bolsões, com denso material histórico do séculos XVIII e XIX cortando o sítio pré-colonial de terra preta. Os bolsões de lixo eram visíveis nos perfis da unidade e continham fragmentos de louças, vidros, grés, cerâmica acordelada, cerâmica torneada, moedas e um ferro de passar roupa a carvão, estando correlacionados à ocupação do século XIX. Em meio aos bolsões históricos foram identificadas manchas de terra preta, com cerâmica de estilo Tapajônico associada a concentrações de carvões. Nas unidades 5, 6 e 7 observou-se o predomínio de vestígios pré-coloniais.

Por fim, a unidade 8 foi aberta em uma área próxima à unidade 2, revelando padrões bastante semelhantes a esta última com a ocorrência de bolsões históricos formados por material construtivo, cerâmica histórica acordelada e torneada, frascos de vidro diversos, grés e louças do século XIX (Figura 5). Esta

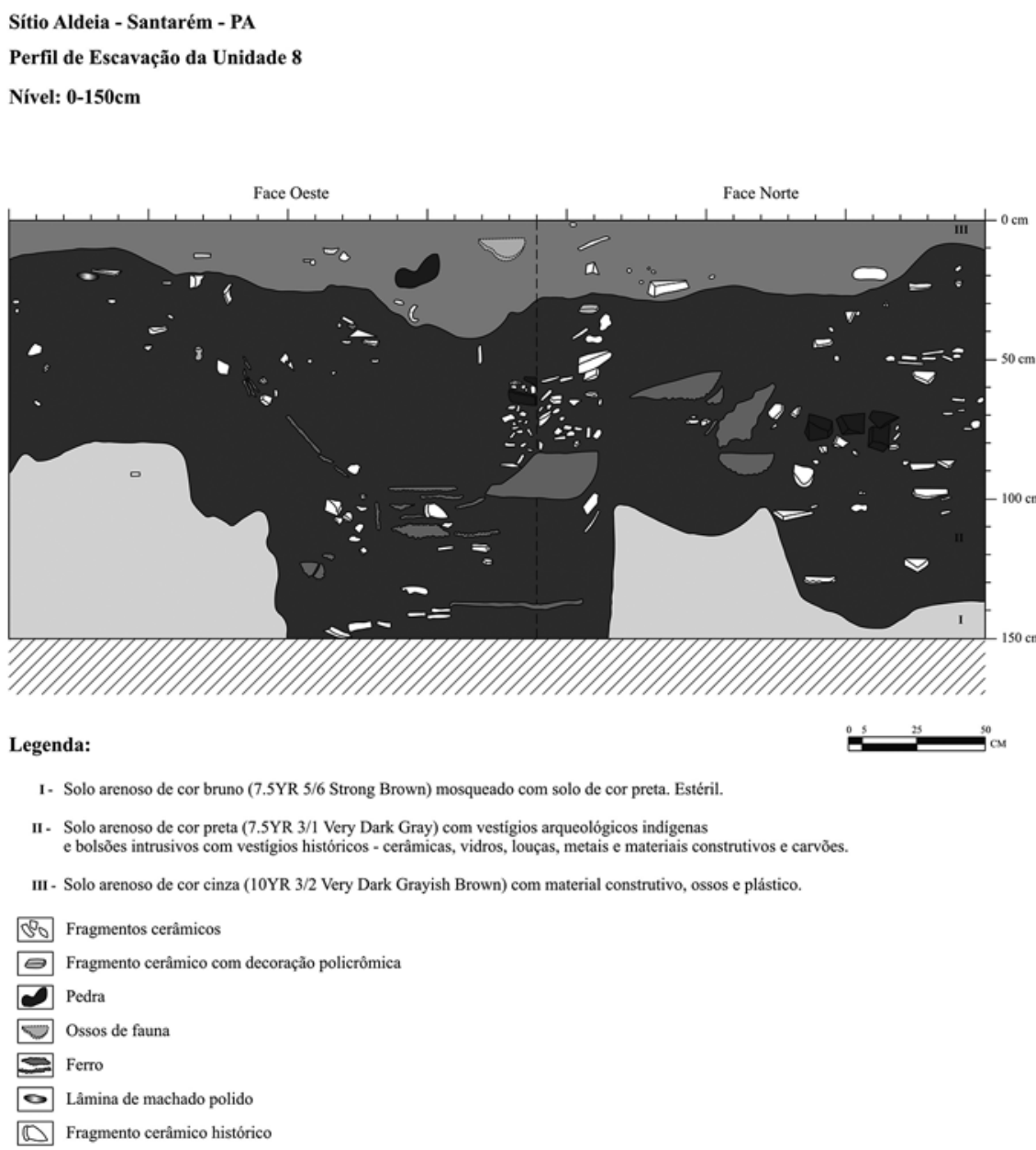

1. Solo arenoso de cor bruno (7.5YR 5/6 Strong Brown) mosqueado com solo de cor preta. Estéril.

Figura 5 - Perfil estratigráfico da unidade 8, indicando os bolsões intrusivos contendo material histórico no estrato pré-colonial. 
40.Ver Tocchetto (2005)

41.Ver Lima (1999). unidade tem particular interesse uma vez que permitiu confirmar os processos formativos do registro histórico, bem como as hipóteses de diferenciação de status social dos ocupantes da cidade Santarém.

$\bigcirc$ sítio Aldeia se revelou um verdadeiro palimpsesto de ocupações atuais, históricas e pré-coloniais. Ao invés de uma massa heterogênea de artefatos pertencentes a distintos períodos, embebidos na matriz de solo de terra preta antropogênica, o que encontramos em algumas áreas foi um sítio pré-colonial cortado por diversos bolsões de lixo histórico, visíveis nos perfis das unidades de escavação, indicando de um lado preocupações de organização com o lixo doméstico, ao menos nas residências do século XIX. Abaixo e no entorno destes bolsões foi possível detectar concentrações de cerâmica indígena indicando a existência de ocupações pré-coloniais preservadas.

Contextos históricos similares, relativos às práticas cotidianas de descarte de lixo de residências do município de Porto Alegre do século XIX, foram discutidos por Tocchetto ${ }^{40}$. Esta pesquisa visou detectar em que medida as evidências materiais confirmavam os discursos de modernidade relacionados a normas de higienização. A autora demonstra que os valores e idéias européias foram apropriados de forma seletiva, reinterpretados e adaptados ao contexto brasileiro. Num século marcado por reformas urbanas, pela ideologia de higienização, surgimento da medicina social, intervenção nos hábitos diários dos indivíduos, normatização da vida pública atuando inclusive no interior das casas, Tocchetto demonstra a existência de depósitos de lixo doméstico dispostos em padrões aleatórios, tanto nos fundos como nas áreas laterais das casas, que remetem à manutenção de antigos hábitos arraigados e à falta de preocupação com as normas de higiene. Contudo, no solar Lopo Gonçalves, uma chácara utilizada como área de lazer pertencente a uma família de elite, na periferia de Porto Alegre, ao lado dos padrões de refugo aleatório foi identificada a existência de bolsões e buracos para deposição de restos orgânicos e inorgânicos, o que implica em certa aproximação com as normas higienistas do século XIX.

Os padrões de descarte de lixo expostos por Tocchetto podem ser comparados aos de Santarém da mesma época. Estas são regiões que, embora apresentassem indícios de uma burguesia emergente, estavam distantes do centro do país. No que tange às práticas de deposição do lixo das unidades domésticas escavadas em Santarém, estas exibiram maior variabilidade do que em Porto Alegre. Duas das unidades de Santarém apresentaram descarte aleatório, enquanto as outras três, localizadas nas proximidades da Praça Rodrigues dos Santos - área onde ficavam os principais edifícios públicos - exibiram nítidos padrões de deposição de lixo em bolsões intencionalmente cavados para este fim. Se compartilharmos das reflexões de Tocchetto, tais padrões representam assinaturas arqueológicas indicativas da assimilação de normas e comportamentos de higiene, ligados a uma burguesia em formação, com ideais de ascensão social.

Conforme discutido por Lima ${ }^{41}$, a contribuição da arqueologia para o estudo deste processo reside na possibilidade de recuperar as evidências materiais 
de práticas cotidianas, rotineiras e anônimas, tão reveladoras do caráter de uma sociedade, e as estratégias de dominação e resistência, que possuem baixa visibilidade. Esta especificidade constitui o grande potencial da disciplina na produção de conhecimento, no âmbito das ciências sociais. Desse modo, o estudo dos processos formativos do sítio Aldeia consistiu numa abordagem que permitiu a identificação de diferentes atitudes das populações históricas com relação ao lixo produzido por elas. Entretanto, outras informações podem ser recuperadas a partir da análise da cultura material de uso cotidiano.

Práticas, espaços, segregação e misturas

Vestígios da ocupação histórica do sítio Aldeia, referentes aos séculos XVIII, XIX e XX, foram recuperados em cinco unidades de escavação, as unidades $1,2,3,4$ e 8 . Neste item a ênfase recairá no material das unidades 2,4 e 8 , dado que a unidade 1 apresentou uma quantidade muito reduzida de material histórico e a unidade 3 somente materiais do século XX.

As unidades 2 e 8 estão situadas na Praça Rodrigues dos Santos, de frente para 0 rio Tapajós. Embora não tenham sido obtidas informações documentais sobre os seus ocupantes nos séculos XVIII e XIX, a disposição espacial dessas unidades é indicativa da posição sócio-econômica dos mesmos, pois o entorno da Praça, onde foi construída a igreja matriz da cidade em 1761, era ocupado pela elite portuguesa e/ou luso-brasileira. Assim, o material arqueológico recuperado dessas duas unidades é, em grande parte, mas não exclusivamente, indicativo das práticas desse segmento sócio-cultural de Santarém. A unidade 4 localiza-se à cerca de 400 metros a sudoeste da Praça, em uma área adjacente ao núcleo central histórico da cidade, iá nas proximidades da aldeia indígena, de modo que seus ocupantes provavelmente estariam enquadrados em um segmento médio dessa sociedade.

Conforme apontam as fontes históricas, nos séculos XVIII e XIX Santarém era composta pelos estratos populacionais português, luso-brasileiro, indígena e mestiço, com uma população indígena multiétnica e espacialmente segregada da portuguesa e luso-brasileira. A população escrava, de origem africana, por sua vez, não compunha um contingente populacional significativo e seus vestígios materiais provavelmente estão misturados com aqueles dos componentes mais numerosos dessa sociedade.

Espaço doméstico, louças e status

Os relatos dos viajantes europeus apontam para mudanças na vida material e nas práticas sociais dos segmentos abastados de Santarém a partir da 
42. Ver Spix e Martius (1981, p. 98-99).

43. Ver Bates (1944, p. 7-9).

44.Ver Kidder (1941,p. 189), Reis Filho (1995, p. 128) e Symanski (1998, p. 81-82).

45. Ver Bates (1944, p. 11).

46. Ver Queiroz (1978, p. 58) e Lima (1999)

47.Ver Lima (1999).

48. Ver Symanski (2002).

49. Ver Miller (1980, 1991). segunda metade do século XIX. Em 1819, Spix e Martius ${ }^{42}$ descreveram as casas da cidade como construídas com paredes de pau-a-pique, barreadas e caiadas de branco, sendo o teto coberto com telhas côncavas ou com folhas de palmeira. Poucas eram as casas com fundamentos e alicerces de alvenaria ou tijolos. Os quartos eram numerosos e, conforme a necessidade, se dividiam em moradia de diversas famílias. Os quintais continham uma cobertura sobre a qual se cozinhava e abrigavam as habitações para a criadagem, quase sempre índios, sendo raros negros ou mulatos. $O$ mobiliário das casas também acompanhava esta tendência de simplicidade, sendo composto geralmente por cadeiras de palhinha ou couro. Redes de algodão branco, finamente tecidas, eram penduradas nas salas exercendo a função de sofás.

Por sua vez, Bates, no início da segunda metade do século XIX, descreveu sobrados de dois e três andares, solidamente construídos com paredes de pedra ou adobe. Nesses sobrados, as salas de visitas eram mobiliadas com um sofá e cadeiras de vime laqueadas e douradas, dispostas em um quadrado ${ }^{43}$, em plena concordância com o padrão das tradicionais salas de visitas oitocentistas do Brasil urbano ${ }^{44}$. Bates ainda se refere a diversas casas comerciais, com gêneros ingleses, franceses, alemães e norte-americanos. $\bigcirc$ grupo mais numeroso nessa época era o dos brancos, portugueses e brasileiros, constituído por negociantes, senhores de escravos, donos de fazendas de gado e de plantações de cacau e borracha, além de autoridades civis e militares. Segundo ele, essa elite tinha "pretensões à civilização", expressas nos costumes muito afetados e formalistas, copiados da capital, os quais incluíam a recepção aos visitantes na sala de visitas. Ele atribuiu esses costumes de inspiração européia à navegação dos vapores no Amazonas, iniciada em 1853, que teria trazido uma nova onda de idéias e modas para a região $0^{45}$.

A descrição de Bates das salas de visitas dos sobrados santarenos como compostas por uma mobília tipologicamente similar e com o mesmo padrão de organização espacial daquela encontrada nas residências dos maiores centros urbanos do Império, sugere que seus proprietários buscavam, a partir de meados do século XIX, se atualizar frente às práticas de sociabilidade já comuns entre os segmentos sociais altos e médios daqueles centros urbanos, então influenciados por um ideal de domesticidade europeu-ocidental que começou a ser adotado no Rio de Janeiro nos anos de $1820^{46}$. Tal influência, contudo, não deve ser considerada como uma reprodução dos modos de vida das elites da corte, dado que o ideal de domesticidade não foi uniformemente incorporado pelos diferentes segmentos sociais do Brasil oitocentista, ocorrendo situações de hibridismo ${ }^{47}$, de incorporação seletiva, e mesmo de rejeição desse ideal em detrimento de outros sistemas de valores ${ }^{48}$. Nesse sentido, o registro arqueológico dessa elite santarena, conforme será discutido, aponta para padrões de vida material modestos.

O estudo comparativo das amostras de faianças finas das unidades 2, 4 e 8, com base na aplicação da escala econômica de Miller ${ }^{49}$ e da variabilidade morfológica, é demonstrativo das diferenças nas condições materiais de vida de seus ocupantes que podem estar relacionadas a variáveis sócio-econômicas, 
práticas culturais e gênero. A escala econômica de Miller, ou "CC Index", baseada em pesquisas em listas de preços de fabricantes ingleses, entre o final do século XVIII e 1880, é uma abordagem utilizada com freqüência para verificar - grau de investimento em louças por parte dos ocupantes de um sítio. Miller ${ }^{50}$ verificou que as faianças finas brancas apresentam o valor econômico mais reduzido, sendo seguidas daquelas minimamente decoradas (shell edges, spatterware, dipped wares, faixas e frisos, etc.). As pintadas a mão, apresentam um custo mais elevado, porém sempre inferior aos das decalcadas na técnica do transfer printing, que são as de valor econômico mais elevado dentre as quatro categorias (Figura 6). O estudo de inventários de proprietários de lojas de louças

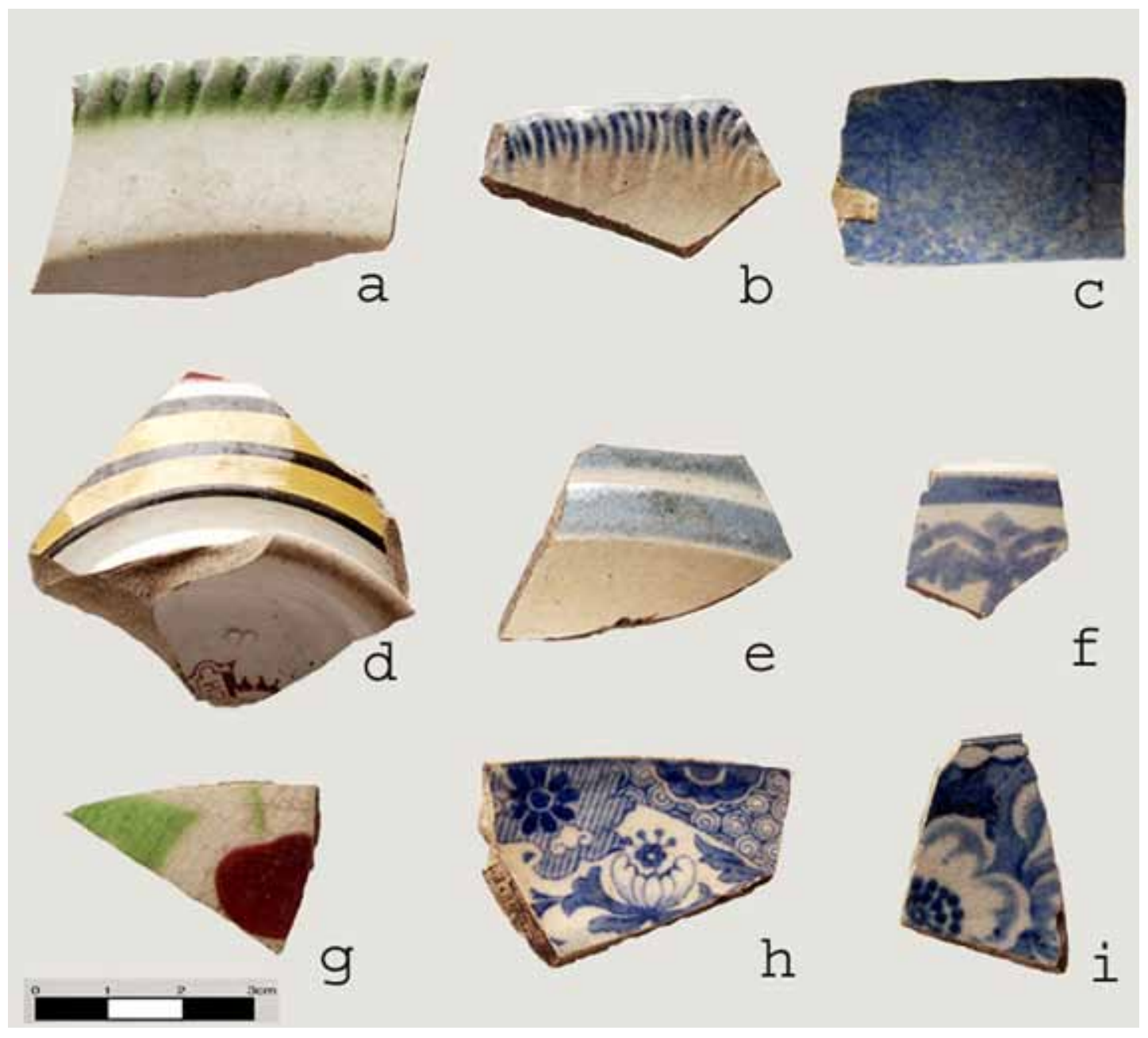

Figura 6 - Faianças finas representativas dos níveis de preços identificados por Miller (1980). Minimamente decoradas: a) shell edged verde, b) shell edged azul, c) spatterware azul, d) dipped ware com faixas e frisos policrômicos, el dipped ware com faixas azuis, f) cut sponge; pintadas a mão: gl peasant style; decalcadas (transfer printing): h) decalcada em azul escuro em padrão floral não identificado, i) decalcada em azul cobalto em padrão floral não identificado. Fotografias: Wagner Souza e Silva. 
de Porto Alegre indicou que, em termos gerais, é possível aplicar esse método às amostras de faiança fina dos contextos brasileiros, dado que a variação nos preços dessas louças se manteve de acordo com a escala de Miller ${ }^{51}$.

As unidades 2 e 8 apresentaram uma maior proporção das louças decoradas manualmente e decalcadas em relação à unidade 4, indicando que seus ocupantes se preocuparam em investir em itens domésticos de maior valor econômico do que aqueles que residiram na unidade 4 (Figura 7). A presença de um pires de porcelana com friso dourado e de uma peça ornamental de porcelana (uma cabeça de cisne) na unidade 2, e de quatro pires de porcelana na unidade 8 , também são indicativos desse maior investimento, dado que os itens de porcelana, ausentes na unidade 4 , são os de mais elevado valor econômico dentre as diversas categorias cerâmicas.

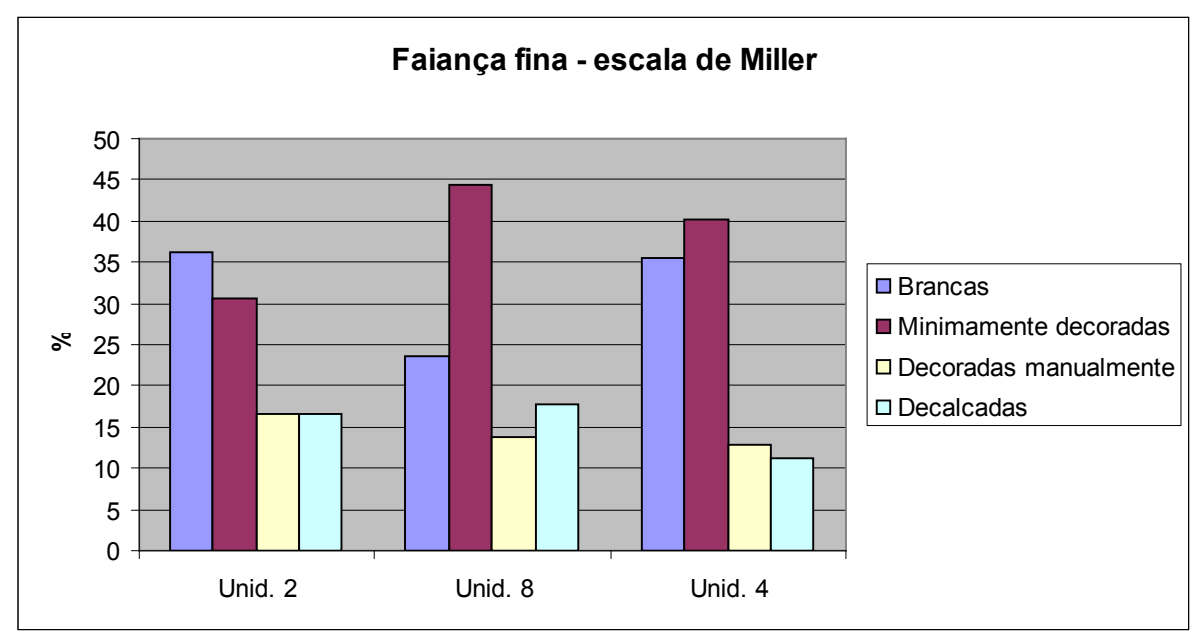

Figura 7 - Aplicação da escala econômica de Miller às faianças finas das unidades 2, 8 e 4 .

Do mesmo modo, a variabilidade morfológica demonstra significativas diferenças nos padrões de uso das louças, com os ocupantes das unidades 2 e 8 apresentando um comportamento material mais sofisticado que aqueles da unidade 4 (Figura 8). Essas diferenças são particularmente evidentes nas desproporções entre xícaras e pires. Dentre as peças destinadas ao consumo de alimentos e de líquidos (como pratos, malgas, xícaras, pires e canecas), as xícaras são as que apresentam maior valor econômico. As unidades 2 e 8 não somente mantêm uma maior proporção de xícaras em relação à unidade 4, como também uma menor desproporção entre essas peças e os pires, indicando que os pires foram predominantemente utilizados como suporte das xícaras. A presença de um bule pintado a mão (Peasant Style) na amostra da unidade 2, e de dois possíveis bules brancos na unidade 8 , também são indicativos dessa preocupação com a segmentação funcional durante o consumo do chá. Já no caso da unidade 4, há uma forte desproporção entre xícaras e pires a favor dos pires, indicando que 


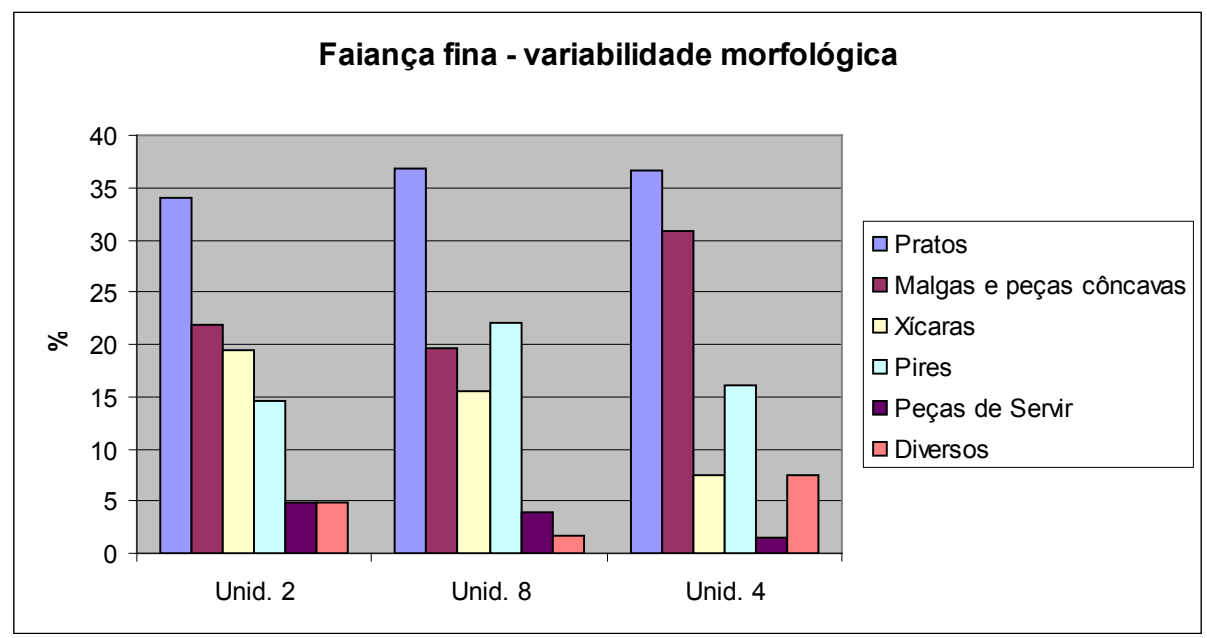

Figura 8 - Variabilidade morfológica das faianças finas presentes nas unidades 2, 8 e 4.

estas peças foram muito mais intensamente utilizadas que aquelas, e assim tiveram usos múltiplos.

A maior proporção de peças de servir nas amostras das unidades 2 e 8 também aponta para o uso de itens domésticos de valor econômico mais elevado, dado que essas peças tendem a ser muito mais caras que aquelas destinadas ao consumo de alimentos. Essa maior proporção de peças de servir é ainda indicativa de uma maior segmentação das refeições, através da exposição dos alimentos e bebidas à mesa em recipientes próprios, ao passo que na unidade 4 provavelmente predominou a exposição de alimentos em cerâmicas de produção local-regional, ou mesmo o serviço diretamente das panelas cerâmicas aonde eram preparados. Por fim, há uma nítida diferenciação na proporção das malgas e peças côncavas entre essas amostras. Malgas são tigelas empregadas no consumo de alimentos como caldos, ensopados, pastas e mingaus, o que parece ser indicativo de uma maior ênfase no consumo desses alimentos na unidade 4 em relação às unidades 2 e 8 , nas quais aparentemente predominou o consumo de refeições mais sólidas, em pratos, com o possível uso de garfos e facas. Retomaremos essa discussão mais adiante.

Verifica-se, portanto, que a condição sócio-econômica mais elevada dos ocupantes das unidades 2 e 8 é expressa pela localização dessas unidades na área nobre da cidade, pelo investimento em louças mais caras, e por uma possível maior complexidade nos padrões de uso desses bens materiais. Essas amostras, contudo, são tão informativas pelas feições a elas ausentes quanto por aquilo que diretamente informam. Destaca-se, assim, que em termos gerais as louças, nessas duas unidades centrais, não compõem aparelhos, apresentam uma baixíssima freqüência de peças para servir, e uma notavelmente baixa freqüência de porcelana. Esse comportamento material deve ser considerado em termos das práticas de sociabilidade na escala local, dado que apresenta-se bastante 
52. Ver Symanski (2002).

53. Ver Spix e Martius (1981, p. 99) e Florence (1977, p. 327).

54. Ver Barbosa (2003) e Florentino e Machado (s.d.)

55.Ver Freyre (2004, p. 138)

56.Ver Oliveira (1988,p.83-88)

57. Ver Spix e Martius (1981, p. 98-99).

58. Ver Florence (1977, p. 329).

59. Ver Baena (2004, p. 22). simplório quando contrastado com aquele dos segmentos médios e altos dos núcleos urbanos do centro-sul do Brasil oitocentista ${ }^{52}$.

A austeridade dos padrões de vida material doméstica dessa elite porługuesa e luso-brasileira está muito provavelmente relacionada à dimensão de gênero. Nesse sentido, cabe ser destacado que o componente português de Santarém, conforme notaram Spix e Martius, em 1819, e Florence, em 182853, era majoritariamente formado por homens. De fato, a imigração portuguesa para o Brasil, desde o início da colonização até o final do século XIX, foi marcada por um enorme predomínio masculino ${ }^{54}$. Freyre já notava que as áreas do Brasil colonizadas por casais portugueses tiveram uma influência européia bem maior do que aquelas áreas, como Santarém, nas quais os homens portugueses tenderam a se unir às mulheres locais ${ }^{55}$.

Por outro lado, o material recuperado das unidades domésticas santarenas é particularmente informativo sobre a agência das mulheres, sobretudo indígenas e mestiças, que ocuparam esses espaços, em seu esforço para a manutenção e redefinição de identidades e de hierarquias sociais.

Mestiçagem, hábitos alimentares e ambiguidades materiais

Em Santarém, unidades domésticas mistas, compostas por homens portugueses e mulheres indígenas ou mestiças, devem ter sido a norma antes que a exceção, dado que os componentes indígena e mestiço, sobretudo os filhos de brancos com índias, chamados mamelucos, constituíam uma parcela significativa desta sociedade. Na Amazônia, o processo de mestiçagem biológica intensificouse a partir de 1755, quando Pombal proibiu a escravidão indígena e criou uma legislação que estimulava o casamento entre brancos e índios, tendo por objetivo a integração dos índios à civilização ${ }^{56}$. Durante sua estada em Santarém, Spix e Martius, referem-se aos homens brancos casados com mulheres indígenas ${ }^{57}$. Com relação à camada mestiça, Florence forneceu a seguinte descrição: "Da mistura de brancos com índias nasce a classe dos mamelucos. Com hábitos mais ou menos indígenas são um tanto mais claros. A língua, porém, é a mesma [a Língua Geral Brasileira]. As mulheres, em geral, são muito silenciosas (...). No pescoço trazem colares e relíquias de ouro, metal que brilha também nas orelhas, e no meio das tranças negras e escorridas da cabeleira. Vão sempre descalças" 58 .

Unidades domésticas mistas, de fato, foram uma situação comum na América colonial hispânica e o mesmo ocorreu em diferentes regiões da América portuguesa, sobretudo na Amazônia, onde o componente indígena manteve-se demograficamente dominante ainda no século XIX $X^{59}$. Pesquisas arqueológicas nos contextos hispano-americanos têm revelado que as feições associadas às mulheres, relacionadas ao processamento e preparo de alimentos, ao gerenciamento da unidade doméstica, e à tecnologia cerâmica de produção local, são predominantemente representadas por elementos nativo-americanos ou mistos, 
euro-afro-americanos ${ }^{60}$. Souza verificou uma situação similar nas unidades domésticas do arraial de mineração setecentista de Ouro Fino (GO), onde as cerâmicas destinadas ao preparo de alimentos apresentavam padrões decorativos incisos de influência africana, tendo sido manipulados por mulheres, majoritariamente escravas, no espaço das cozinhas, ao passo que faianças portuguesas e tigelas de cerâmica pintada eram empregadas por homens nas áreas de sociabilidade das residências ${ }^{61}$.

Nas unidades domésticas de Santarém essas misturas não se limitaram à família nuclear, mas incluíram também os serviçais co-residentes, os quais, conforme notaram Spix e Martius ${ }^{62}$ no começo do século XIX, eram quase que exclusivamente índios "...sendo raros pretos ou mulatos". Esses trabalhadores(as) domésticos viviam em habitações nos quintais das casas. Nesse sentido, o registro arqueológico das unidades domésticas estudadas, antes do que produto exclusivo da camada branca, portuguesa e luso-brasileira, é, em realidade, resultante das práticas de grupos com identidades diferenciadas, que podem ter incluído maridos portugueses ou luso-brasileiros, esposas indígenas ou mestiças, filhos brancos ou mestiços, e serviçais indígenas, mamelucos, e, em menor escala, africanos e afrodescendentes. Nesse caldeirão cultural, corpos e práticas diferenciadas mesclaramse, resultando em um registro arqueológico ambíguo, simultaneamente indicativo de hábitos, práticas e aspirações de influência européia e indígena.

A exemplo das unidades domésticas coloniais hispano-americanas, a cerâmica de produção local, acordelada, feita com tecnologia nativa, é uma categoria comum às unidades domésticas de Santarém, constituindo, nos casos em estudo, entre 9\% e 12\% das amostras cerâmicas (Figura 9). Segundo Bates, a "cerâmica grosseira" dos utensílios de cozinha da cidade, que incluíam panelas,

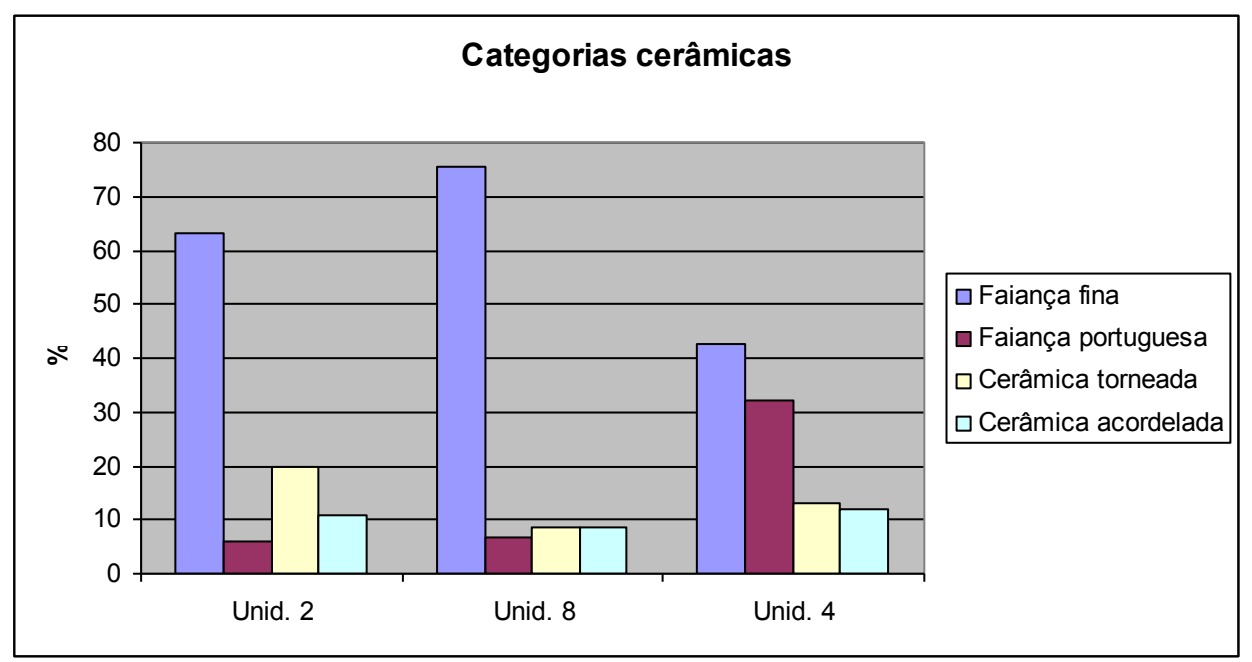

Figura 9 - Freqüência das categorias cerâmicas (faiança fina, faiança portuguesa, cerâmica torneada e cerâmica acordelada) presentes nas unidades 2,8 e 4 .
60.Ver Deagan (2003, p. 7-8).

61. Ver Souza (2002)

62. Spix e Martius (1981, p. 98-99). 
65. Ver Morales (2000).

66. Ver Zanettini (2005)

67. Ver Morale (2000) caçarolas, fornos de mandioca, tigelas, bacias e outros utensílios, era feita com argila branca e dura de um leito situado na enseada do Maicá, a leste da cidade. A essa argila eram misturadas cinzas de cascas de árvores silicosas chamada caraipé (Licania turuiva), que davam grande firmeza às peças. Ele ainda informa que o caraipé era vendido em feixes, nos armazéns de quase todas as cidades da região ${ }^{63}$

Essa produção de vasilhames cerâmicos era um ofício tipicamente feminino, assim como as atividades domésticas de processamento e cocção dos alimentos. A técnica de construção desses vasilhames, na esmagadora maioria das amostras em questão, é o acordelado, sendo o cariapé o tipo de antiplástico de maior popularidade. Ambas tecnologias são indígenas. Entretanto, o padrão acima descrito representa uma escolha tecnológica do período histórico que se distingue das indústrias cerâmicas indígenas pré-coloniais da região de Santarém, cujo antiplástico cerâmico predominante era o cauixi - espículas de esponjas de água doce - misturado ao caco moído, embora se registre o emprego do cariapé, bem como outras inclusões ${ }^{64}$. Cabe ser destacado que vasilhames com antiplástico de cauixi estão presentes, ainda que em baixa popularidade, nos contextos históricos do sítio Aldeia.

Autores tais como Morales ${ }^{65}$ e Zanettinibo interpretam a cerâmica histórica de produção local-regional - conforme denomina este último - como produto de um processo de transculturação. Ao analisar a cerâmica colonial de Jundiaí (SP), Morales ${ }^{67}$ chamou a atenção para a grande diversidade da cultura material proveniente de contextos relativos às influências indígenas, africanas e europeias. Entretanto, não é isto o que se observa em Santarém (Figura 10). Num primeiro momento, poderíamos facilmente nos render a uma interpretação que valorizaria a uniformidade da cultura material histórica local, enfatizando a substituição de uma tradição pré-colonial por outra que guarda pouca semelhança em termos formais e tecnológicos, ao eleger o emprego do cariapé como antiplástico e introduzir determinadas formas de influência européia. Consequentemente, a avenida para conclusões que enfatizam processos de aculturação estaria aberta.

A análise detalhada dos vestígios cerâmicos de produção local, provenientes das amostras do sítio Aldeia, revelou na unidade 4 a presença de um assador de mandioca com decoração histórica, embora fabricado com o emprego do cauixi. Esta correlação (decoração histórica X uso do cauixi), sugestiva de processos de trocas culturais, tem se repetido em algumas amostras de outras unidades (6 e 7) que ainda se encontram em processo de estudo. Desse modo, tais influências mais do que invisíveis são de fato sutis, indicando a importância dos estudos de cultura material para a compreensão do universo colonial, sobretudo em áreas periféricas.

Embora não existam evidências de que os vasilhames cerâmicos tenham sido produzidos nessas unidades, eles, de fato, foram manuseados por mulheres indígenas ou mestiças no espaço da cozinha, a qual situava-se no quintal das residências. Dentre as formas identificadas, a mais popular em todas as 


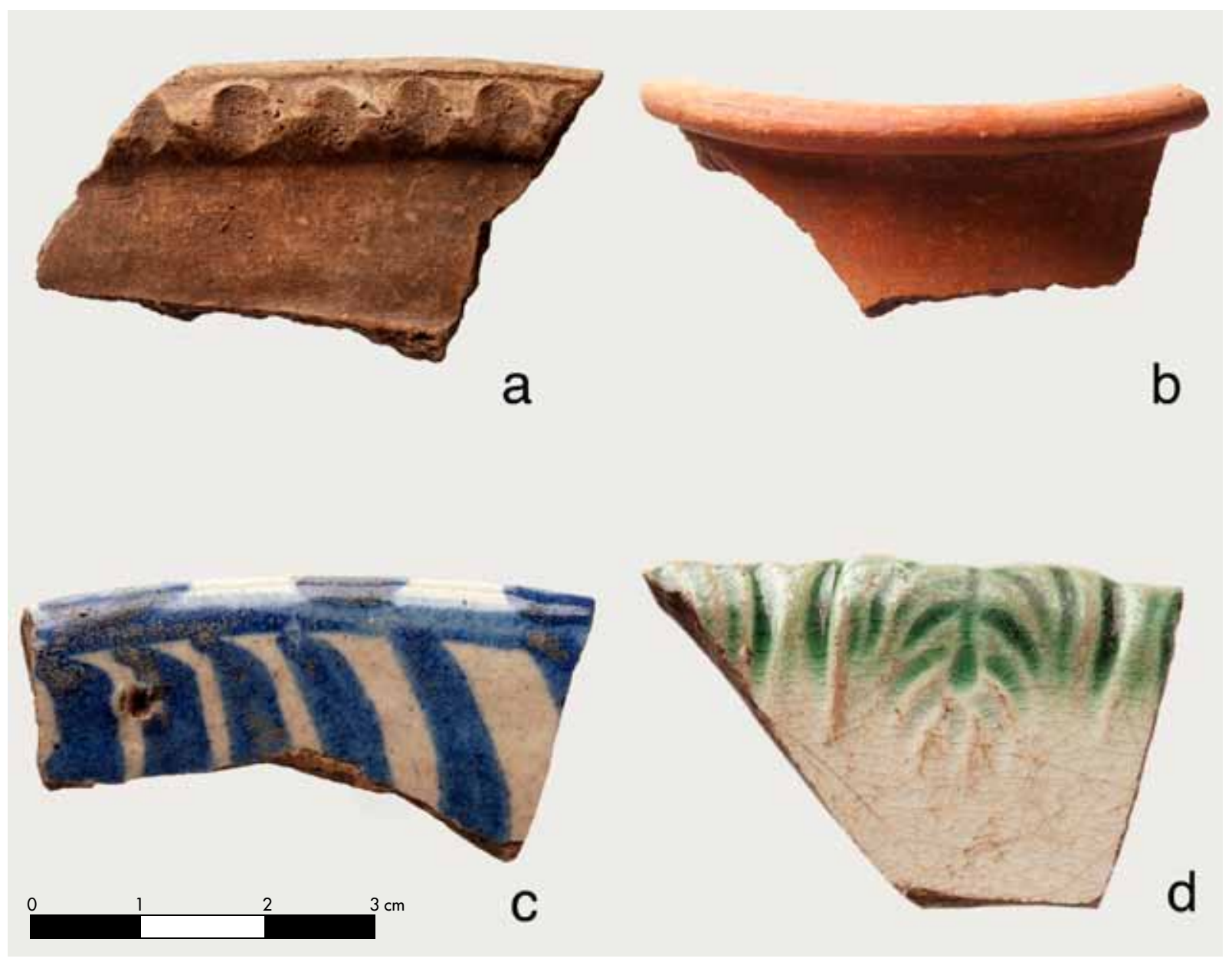

Figura 10 - Os quatro tipos cerâmicos mais populares nos contextos históricos de Santarém: a) cerâmica acordelada com antiplástico de cariapé decorada com um filete aplicado com digitado junto à borda, b) cerâmica torneada destinada à estocagem, c) fragmento de peça côncava de faiança portuguesa decorada em azul, d) fragmento de borda de prato de faiança fina, padrão shell edged verde. Fotografias de Wagner Souza e Silva.

amostras é a das panelas destinadas ao cozimento de alimentos, ocorrendo ainda o referido assador de mandioca na unidade 4 e uma bacia na unidade 2. Essas peças tendem a ser decoradas de modo simples, geralmente com apenas um filete aplicado junto à borda, com decoração digitada ou entalhada, não ocorrendo decorações pintadas.

Conforme indicado no gráfico da figura 9 as cerâmicas produzidas em torno (torneadas) também são onipresentes, compondo entre $8,7 \%$ e $20 \%$ das amostras cerâmicas. Diferentemente das cerâmicas acordeladas, de produção artesanal, local, as peças torneadas eram produzidas em oficinas especializadas, as olarias, e podem remeter a esferas de interação regional ou mesmo nacional. Verifica-se que a maioria das formas passíveis de reconstituição desses vasilhames destina-se à estocagem, tanto de líquidos quanto de sólidos, e minoriariamente à 
transferência de líquidos (Figura 11 ). Há, assim, uma dicotomia funcional bem estabelecida entre os vasilhames cerâmicos acordelados, artesanalmente produzidos, quase que exclusivamente destinados à cocção de alimentos, e os vasilhames torneados, produzidos em olarias, e destinados à estocagem e à transferência de líquidos.

Outra feição comum às amostras é a grande popularidade das louças côncavas, incluindo malgas, as quais estão relacionadas ao serviço e consumo de alimentos, sobretudo na forma de ensopados e cozidos. Conforme já discutido, essas louças são mais populares na amostra da unidade 4 do que nas unidades 2 e 8 , o que, aparentemente, sugere uma maior ênfase no consumo de ensopados e caldos naquela do que nestas. Porém, ao se contrastar as freqüências somente de pratos e de louças côncavas nos três contextos, verifica-se que estas últimas responderam por aproximadamente $50 \%$ das louças destinadas ao consumo de alimentos nos três contextos, demonstrando que o consumo de alimentos ensopados foi intenso em Santarém (Figura 12).

\section{Cerâmica Histórica - Século XIX - Sítio Aldeia, Santarém, PA}

Cerâmica Acordelada
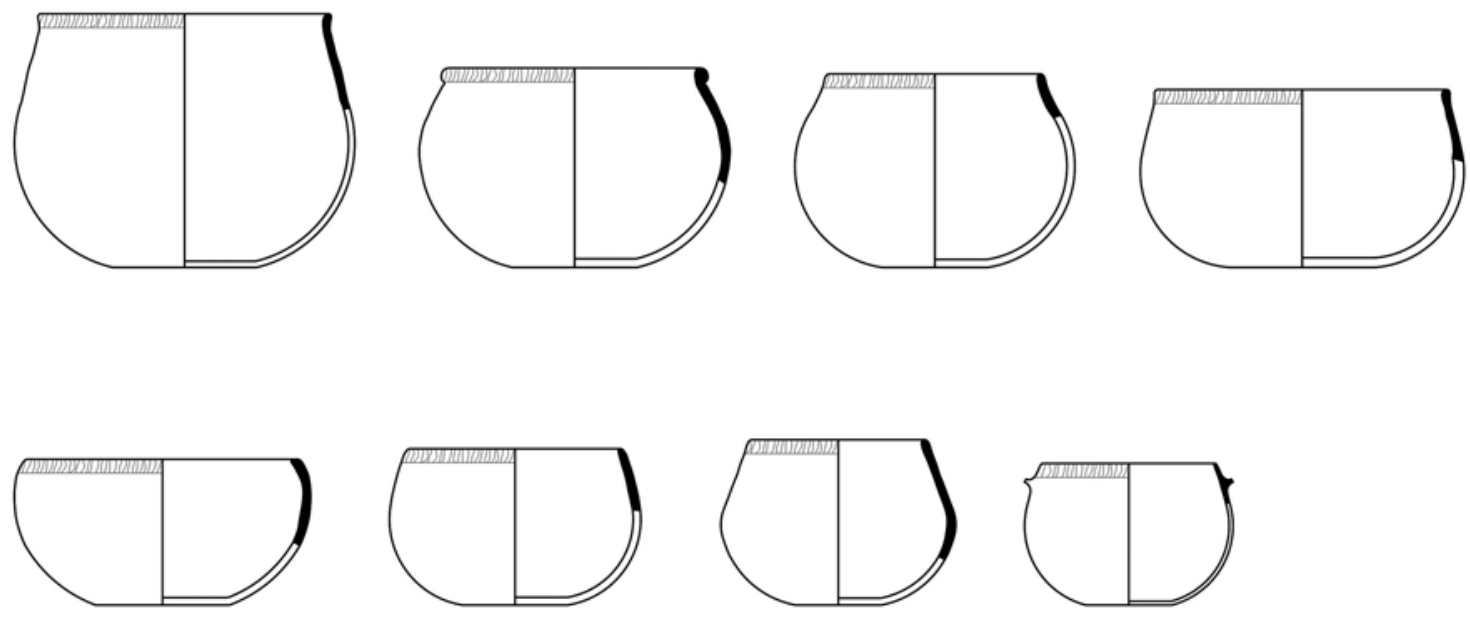

Cerâmica Torneada
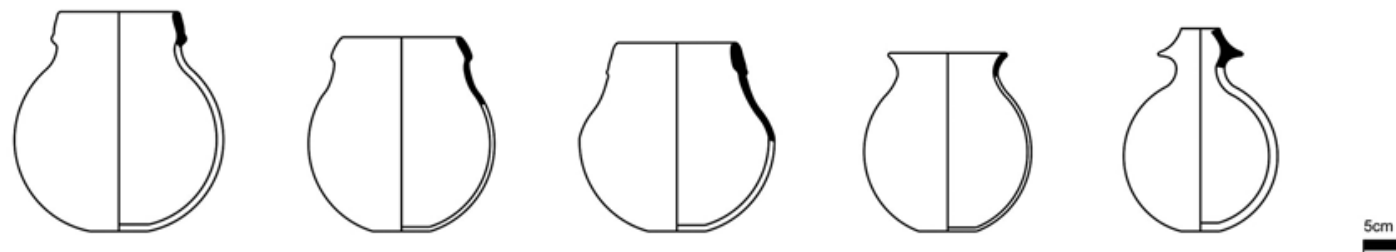

Figura 11 - Morfologia das cerâmicas históricas acordeladas e torneadas presentes nos contextos de Santarém. 


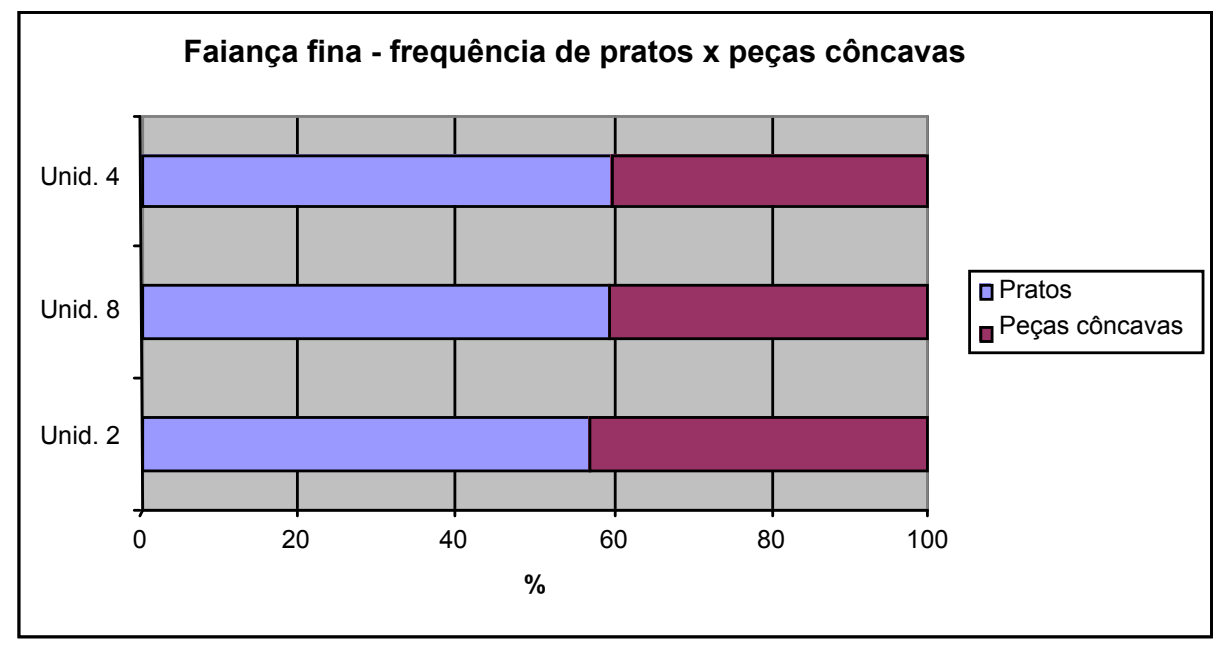

Figura 12 - Freqüência de pratos x peças côncavas de faiança finas nas unidades 4, 8 e 2

Esta alta proporção de louças côncavas está em desacordo com a variabilidade morfológica comumente verificada nos sítios urbanos do Brasil oitocentista, onde a frequência de pratos tende a predominar fortemente sobre as demais peças, indicando um maior consumo de alimentos sólidos, geralmente consumidos com talheres em pratos individualizados, em consonância com a ideologia individualista do capitalismo industria|b8. Também não foi comum nas casas grandes dos engenhos de Chapada dos Guimarães, embora tenha sido verificada em algumas das unidades associadas a escravos desses estabelecimentos 69 .

Como bem lembra Appadurai, a alimentação consiste em um componente básico da identidade individual e de grupo, podendo servir tanto para indicar e construir relações sociais baseadas na igualdade, intimidade e solidariedade, quanto para sustentar relações caracterizadas por hierarquia, distância e segmentação ${ }^{70}$. Deve ser considerado que mesmo grupos e indivíduos desprovidos têm a possibilidade de exercer escolhas no que concerne à preparação e consumo de alimentos, o que faz do domínio da alimentação um lócus fundamental de identidade, conformidade e resistência ${ }^{71}$. Para o caso de Santarém, a grande proporção de louças côncavas em todos os contextos é uma evidência da manutenção de hábitos alimentares tradicionais, com ênfase no consumo de sopas e caldos, que eram sorvidos diretamente dessas peças, sem o auxilio de talheres ${ }^{72}$. Esses hábitos alimentares tinham raízes fincadas tanto na sociedade camponesa de Portugal do Antigo Regime quanto nas sociedades indígenas amazônicas.

Na Europa Ocidental do Antigo Regime as sopas constituíam um dos principais pratos dos camponeses. Segundo Flandrin a sopa "..constituía o prato essencial e geralmente único de todas as refeições feitas em casa..." 73. Para os camponeses de Portugal a situação não era diferente ${ }^{74}$. No Brasil colonial,

68.Ver Lima (1999), Symanski (1998, p. 208; 2002)

69. Symanski (2006, p. $217-$ 229) e Symanski e Souza (2007, p. 225, 232).

70. Symanski Appadurai (1981, p. 494).

71. Symanski Smith (2006, p. 480).

72. Symanski Cascudo (1983, p. 709-710).

73. Symanski Flandrin (1998, p. 593).

74. Symanski Cascudo (1983, p. 586). 
75. Idem (1983, p. 587).

76. Idem, (1983, p. 149).

77. Idem (1983)

78.Ver Sampaio (1944,p. 73 75) Ver

79.Ver Gruzinski (2001,p. 48)

80.Ver Mignolo (1995), apud Gruzinski (2001, p. 48).

81. Ver Groover (1994)
Cascudo nota que a sopa logo reapareceu nas residências portuguesas: "Os pobres mastigavam a sopa, suprindo refeição pela massa das verduras e carnes, e os de recursos maiores sorviam-na nos pratos côncavos da louça lisboeta. Ou nas malgas e tigelas" 75 .

Nas sociedades indígenas amazônicas também era comum o consumo de alimentos líquidos, embora predominassem os assados e tostados. Cascudo lista como alimentos líquidos de consumo recorrente os mingaus, que consistiam em fervidos de farinha, tapioca, e carimã, os vinhos de açaí e bacaba consumidos com farinha, e os caldos de carne e peixe, que eram espécies de pirões ralos ${ }^{76}$. Alimentos líquidos são ainda muito populares na culinária tradicional da região amazônica, como é o caso do tacacá, um ensopado de camarão com goma de mandioca, servido em cuias ou tigelas, o qual, segundo Cascudo ${ }^{77}$, deriva de um caldo indígena denominado mani poi. Sampaio lista outros ensopados típicos da região, como a maniçoba, uma caldeirada de folhas de maniva com miúdos de boi e de porco, e o chibé, uma mistura do fruto do imbuzeiro com leite, ou de farinha de mandioca com água, que é tomado em cuias $^{78}$.

Parece ter ocorrido assim, nessas unidades domésticas mistas de Santarém, uma interessante convergência nos hábitos alimentares de portugueses e indígenas, na qual os ensopados atuaram como um denominador comum, servindo para entrelaçar universos culturais disparatados. Ao problematizar a questão da mestiçagem na América colonial, Gruzinski chama a atenção para a tendência à polarização entre dois blocos comumente tidos como impermeáveis, os índios vitimizados e os europeus vilanizados, a qual imobiliza e empobrece a realidade, ao desconsiderar não somente as trocas entre esses grupos, mas também o papel dos indivíduos e grupos intermediários, que transitaram entre esses dois grandes blocos ${ }^{79}$. Ele observa que os espaços de mediação tiveram um papel essencial na história da colonização, pois são nesses espaços "...que aparecem e se desenvolvem novos modos de pensamento cuja vitalidade reside na aptidão para transformar e criticar o que as duas heranças, ocidental e ameríndia, têm de pretensamente autêntica" ${ }^{\prime 80}$. No caso de Santarém, a cozinha consistiu em um desses espaços de mediação, o que faz das cozinheiras, indígenas e mestiças, que, sob a supervisão das mulheres dos chefes da casa muitas destas também mestiças -, processavam e cozinhavam os alimentos em vasilhames cerâmicos produzidos por outras mutheres da mesma condição social, agentes intermediários deste processo de trocas culturais que resultou na rica cultura nortista, que tem na culinária uma das suas feições mais marcantes.

Groover, ao discutir as evidências materiais de unidades domésticas multiculturais em um contexto de fronteira de Carolina do Sul, Estados Unidos, observa a cultura material socialmente visível, como a arquitetura e os utensílios relacionados às refeições formais, tipicamente reflete as tradições dos colonizadores principais, ao passo que aquela de baixa visibilidade tende a exibir uma síntese de tradições culturais ${ }^{81}$. Para Santarém, conforme já discutido, muito da cultura material de baixa visibilidade, como os vasilhames cerâmicos acordelados, está relacionado às esferas de atuação femininas, sobretudo no 
espaço da cozinha. Esses vasilhames cerâmicos, assim, remetem a misturas, culinárias e culturais, mas também a segregação, às fronteiras entre casa e cozinha, homens e mulheres, patrões e serviçais, e brancos e não-brancos.

Poderia ser esperado que essas desigualdades na escala do espaço doméstico santareno estivessem também expressas no domínio do consumo dos alimentos, com os senhores favorecendo aqueles sólidos, consumidos em pratos individualizados, consonante com os hábitos burgueses que estavam se consolidando no Brasil, em detrimento dos ensopados, de cunho mais tradicional. Esta situação poderia ser indicada pelo investimento em pratos de maior valor econômico, decalcados, enquanto as louças côncavas, se majoritariamente destinadas aos serviçais, seriam as mais baratas e grosseiras, brancas e minimamente decoradas. As louças, porém, apresentam dimensões de variação pouco significativas em termos de níveis de preços entre as duas categorias funcionais, sugerindo que o consumo de alimentos sólidos, em pratos, e de ensopados, em louças côncavas, foi generalizado entre esses segmentos sóciosculturais (Figura 13). Essa convergência no domínio do consumo de alimentos aponta para uma ambigüidade nas relações de poder na esfera doméstica, pois aparentemente sugere, seguindo as proposições de Appadurai ${ }^{82}$, um esforço na construção de relações sociais baseadas na igualdade, intimidade e solidariedade, antes do que na hierarquia, distância e segmentação que, definitivamente, marcavam as relações entre o patrão branco, português ou luso-brasileiro, e o/a serviçal indígena ou mestiço(a).

Fora da esfera do preparo e consumo de alimentos, um tipo de artefato bastante comum nos contextos históricos de Santarém são os cachimbos artesanais de argila ${ }^{83}$. Produzidos por meio da tecnologia indígena, inclusive com o uso do cariapé, esses cachimbos apresentam-se em uma diversidade de formas e decorações, embora predomine um tipo simples, sem decoração. Dentre os

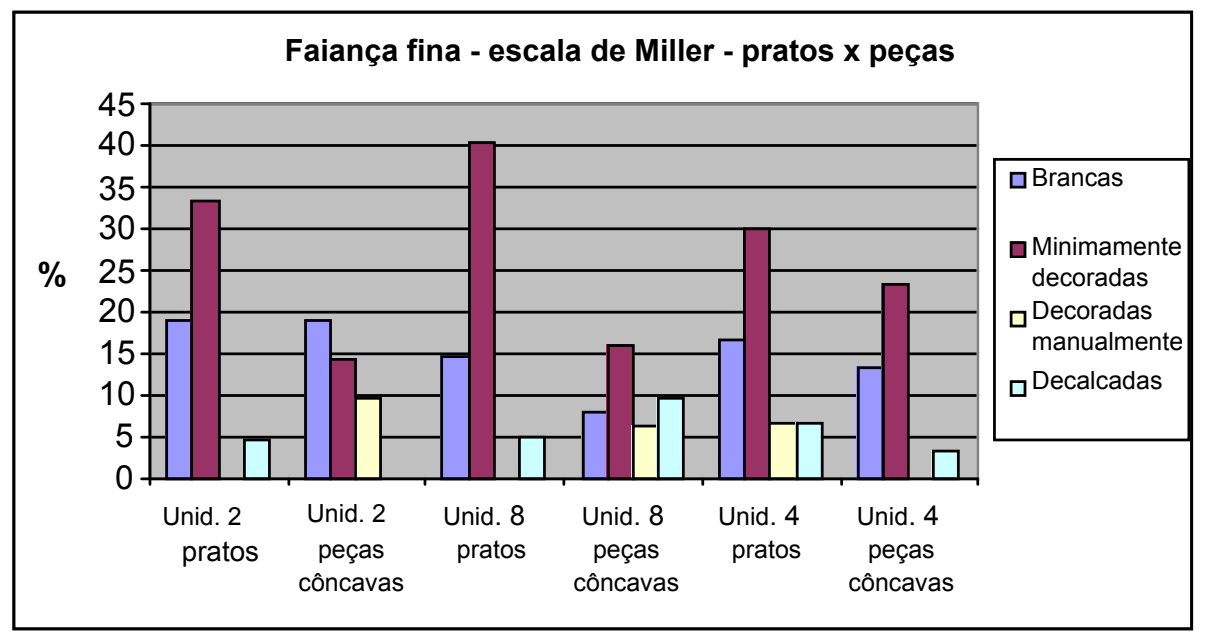

Figura 13 - Aplicação da escala de Miller aos pratos e peças côncavas das unidades 2 , 8 e 4 .
82. Ver Appadurai (1981, p. 496).

83. Ver Barata (1951). 
84. Idem, p. 190.

85. Ver Agostini (1998)

86. Ver Barata (1951)

87. Idem, p. 192-193. decorados, muitos apresentam ornamentação de estilização vegetal nos modelos do barroco português, os quais se repetem na prata lavrada jesuítica, na arquitetura e no mobiliário, sobretudo nas obras de talha em madeira dos púlpitos das igrejas ${ }^{84}$ (Figura 14). Para o centro-sul do Brasil, há uma rica iconografia oitocentista que retrata os cachimbos de barro nas bocas dos escravos e da população afro-descendente, o que levou Agostini a estudar o papel desses artefatos na construção de identidades escravas e nas estratégias de resistência deste grupo à cultura dominante ${ }^{85}$. Em Santarém, contudo, a população afrodescendente teve pouca significânwcia demográfica, de modo que Barata já considerava que esses artefatos eram produzidos pelos índios em estado de aculturação, sob influência dos jesuítas, entre o fim do século XVII e o século XVIII, e por índios aldeados e por caboclos no século XIX ${ }^{86}$. Barata ainda propôs a hipótese de que teriam sido produzidos por homens, razão pela qual seus ornatos estariam ausentes dos vasilhames cerâmicos ${ }^{87}$.

As três unidades aqui analisadas apresentaram cachimbos, em número de um na unidade 2 , um na unidade 8 , e dois na unidade 4 . O cachimbo da unidade 2 é simples, apresentando somente uma borda reforçada externa e incisões verticais. $O$ da unidade 8 também é simples. Na unidade 4 , um dos cachimbos apresenta apenas um filete aplicado e ungulado junto à borda, ao passo que o outro contém uma elaborada decoração barroca. É, contudo, arriscado atribuir o uso desses cachimbos somente à população indígena ou mestiça de Santarém. Embora a produção dessas peças fosse, provavelmente,

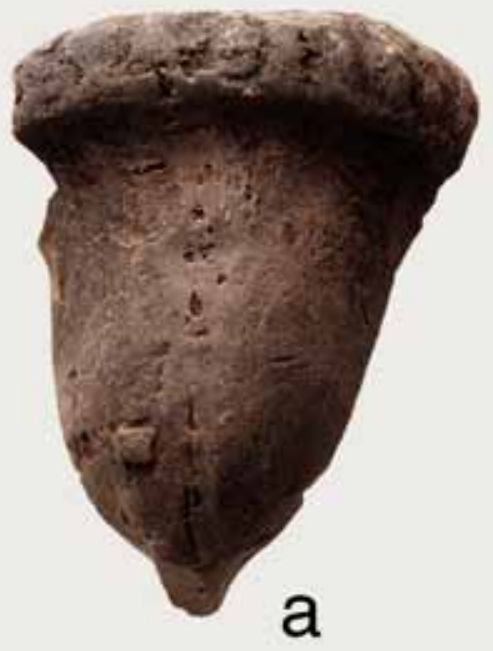

0

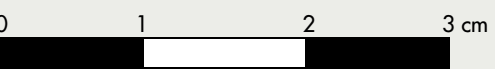

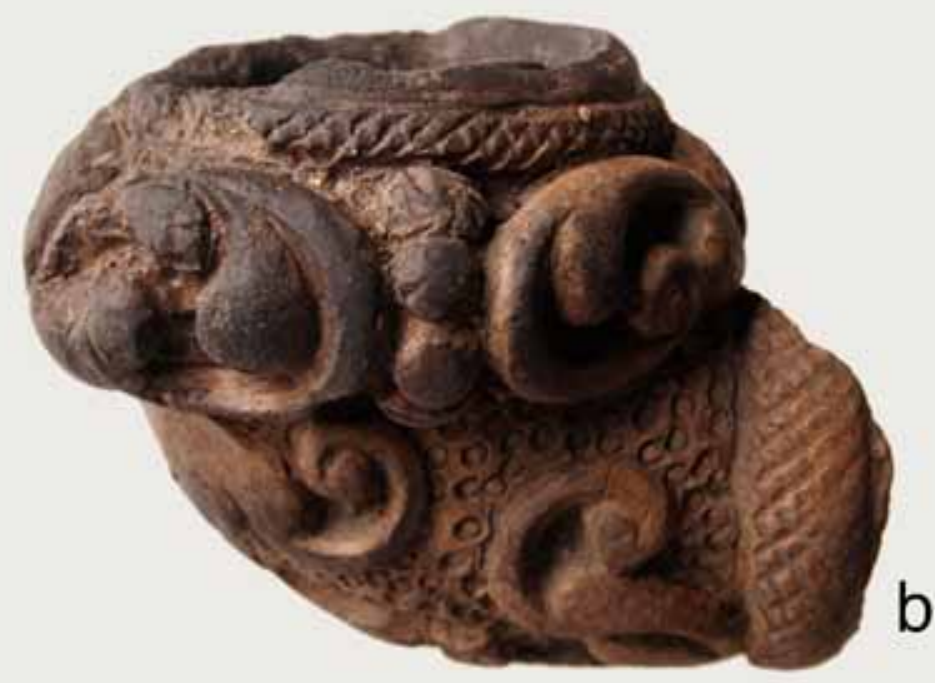

Figura 14 - Cachimbos cerâmicos encontrados nos contextos históricos de Santarém: a) tipo simples, decorado somente com um filete aplicado ungulado, junto à borda, b) tipo ornamentado com estilização vegetal. Crédito das fotos: Wagner Souza e Silva. 
atrelada a esses grupos, seu uso pode ter sido mais amplamente disseminado nessa sociedade, como parece ter ocorrido em outras regiões do Brasil fortemente marcadas pela mestiçagem entre indígenas, africanos e portugueses, como Mato Grosso e Maranhão.

Florence, ao visitar a região de Chapada dos Guimarães (MT), em 1827, descreveu uma senhora de engenho que passava os dias fumando um longo cachimbo, em tudo similar aos usados pelos escravos ${ }^{88}$. Aluísio Azevedo (1857-1913), em seu livro O Mulato, faz diversas alusões ao uso de cachimbos de barro pela camada senhorial maranhense, sobretudo os senhores de engenho e fazendeiros, como era o caso de Sebastião Campos, que permanecia na sua rede "...durante horas esquecidas, em ceroulas fumando o seu cachimbo de cabeça preta, fabricado na província"; de dona Maria Bárbara, uma velha maranhense de ascendência portuguesa criada na fazenda, que fumava um "enorme cachimbo de taquari do Pará"89.

Assim, a exemplo da maioria das louças e dos vasilhames cerâmicos, os cachimbos das unidades domésticas de Santarém são ambíguos em termos das identidades de seus usuários, podendo ter sido utilizados tanto pelos serviçais indígenas e mestiços quanto pelos portugueses e luso-brasileiros. Em um campo fortemente marcado por mestiçagens e trocas culturais esses objetos, inicialmente associados a uma prática tradicional indígena, foram reapropriados por grupos e indivíduos vinculados a diferentes referenciais sociais e identitários. A incorporação de uma iconografia barroca a parte desses objetos é mais um dos exemplos desse processo de mestiçagem que resultou na formação de uma cultura híbrida, luso-indígena, na região amazônica.

Desigualdades e escolhas culturais

Se as semelhanças entre as amostras sugerem misturas que apontam para a conformação de uma elite local culturalmente mestiça, algumas outras feições são indicativas da manutenção de fronteiras sócio-culturais, tanto no interior dos espaços domésticos quanto entre as unidades estudadas.

Embora o domínio das refeições principais, realizadas predominantemente com pratos e tigelas de louças baratas, não pareça expressar hierarquia e segmentação, tendo sido marcado por uma amálgama de tradições, as desigualdades sociais na escala dessas unidades são mais evidentes no domínio do consumo do chá. Ao contrário do jantar, que era dominado pelo homem, o consumo social do chá tornou-se, na Europa ao longo do século XVIII, um domínio regido pela mulher, com regras e etiquetas próprias. No Rio de Janeiro imperial o consumo social do chá, apesar de ter adquirido feições diferenciadas das européias, foi incorporado pelas elites e segmentos médios, tornando-se, como na Europa, uma esfera de atuação feminina ${ }^{90}$.
88. Ver Florence (1977, p. 109-110).

89. Ver Azevedo (s.d., 62-63, 88). A obra foi escrita em 1881.

90.Ver Lima, 1997. 
No caso das amostras de Santarém as louças de chá foram os itens domésticos que mantiveram a maior visibilidade social, pois tenderam a ser as peças de maior valor econômico, conforme pode ser observado na Figura 15. Embora a unidade 8 pareça expressar menos claramente esta tendência, deve ser considerado que, nesta unidade, todas as peças de porcelana - a categoria de louça de maior valor econômico - estão relacionadas ao consumo do chá. É, contudo, arriscado atribuir essa variabilidade a práticas sociais referentes à agência feminina, como ocorreu no caso do Rio de Janeiro ${ }^{91}$, sem pesquisas documentais mais intensas. De qualquer modo, esses dados sugerem que, nessas unidades domésticas santarenas, as louças de chá foram as mais socialmente significativas, de modo que as fronteiras na prática social, demarcadas entre patrões e empregados, e, mais provavelmente, entre patrões e empregadas, são bem mais evidentes neste domínio do que no do jantar.

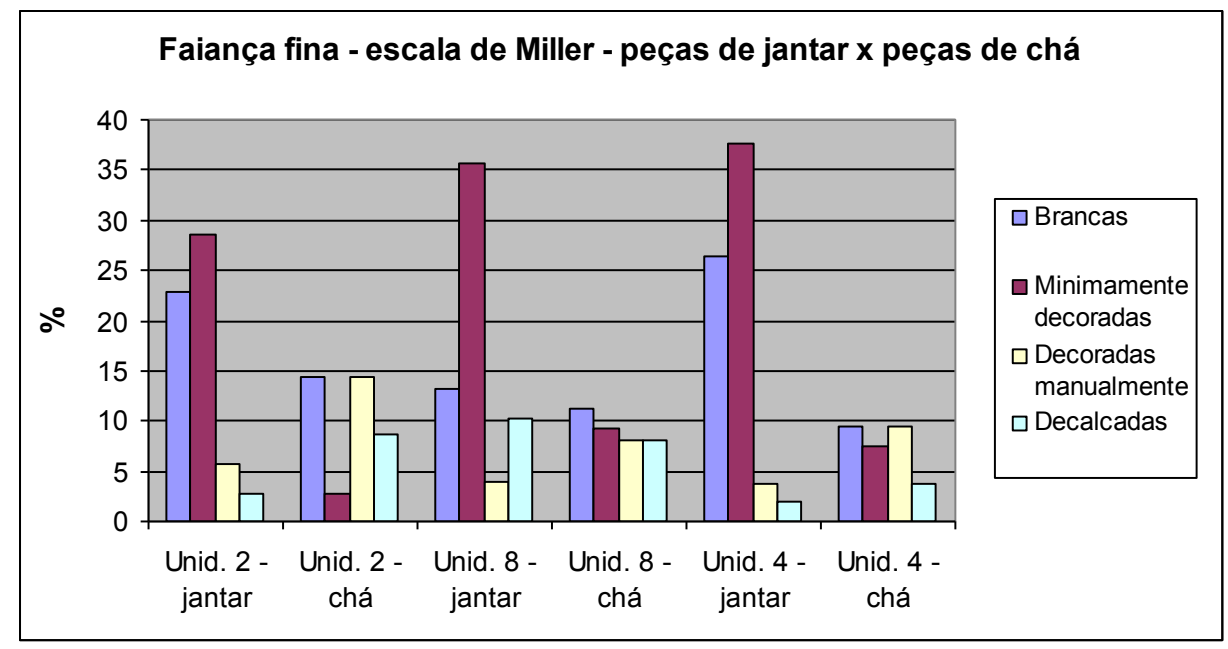

Figura 15 - Aplicação da escala econômica de Miller às peças de jantar e às peças de chás de faiança fina das unidades 2,8 e 4 .

As diferenças entre as amostras, por sua vez, apontam para a manutenção de práticas e de referenciais mais conservadores entre os ocupantes da unidade 4, sugerindo que a influência indígena pode ter sido mais intensa nesta unidade do que nas unidades 2 e 8 . Isto é indicado pela presença de um assador de mandioca, fabricado de acordo com uma tecnologia indígena, com uso do cauixi, mas com decoração histórica exclusivo desta unidade, e pela maior popularidade de louças com padrões decorativos em cut sponge llouças estampadas com motivos sequenciais geométricos ou fitomorfos - vide figura 6 - fl e dipped ware banded (louças decoradas com argilas coloridas em faixas - vide figura $6-d, e)$. As louças decoradas na técnica do cut sponge são praticamente exclusivas desta unidade, onde perfazem 5,9\% da amostra de faianças finas, ocorrendo apenas um fragmento na unidade $810,8 \%$ da amostra de faianças 
finas) e estando ausentes da unidade 2. Já as louças dipped, embora ocorram nas três unidades, são mais populares na unidade 4 , onde representam $5,9 \%$ da amostra de faianças finas, contra $4,9 \%$ na unidade 2 e $4 \%$ na unidade 8 .

Oassador de mandioca, de manufatura acordelada com antiplástico de cauixi, decorado com entalhe junto à borda, indica que os ocupantes da unidade 4 mantiveram a prática indígena do preparo da farinha de mandioca, e assim a manutenção de hábitos alimentares típicos da população indígena amazônica, nos quais a farinha de mandioca constitui, nas palavras de Cascudo, "... o conduto essencial e principal, acompanhando todas as coisas comíveis, da carne à fruta"92. Em uma recente revisão acerca desses utensílios cerâmicos, encontrados em contextos de diversas regiões do Brasil entre os séculos XVII e XIX, Souza os relaciona à posição ocupada pelos indígenas no universo colonial, embora, posteriormente, tivessem sido incorporados pelos escravos africanos e afro-descendentes ${ }^{93}$. Para o caso do assador da unidade 4, é ainda importante considerar que este consistiu em uma das raras peças, dentre as amostras analisadas, que apresentou antiplástico de cauixi, o qual, como já informado, era o tipo de antiplástico predominante nas indústrias cerâmicas pré-coloniais da região de Santarém. Este fato sugere que alguns dos ocupantes da unidade em questão podem ter mantido certos elementos de uma memória ancestral indígena, vinculados ao preparo da farinha de mandioca em assadores produzidos com um tipo específico de antiplástico típico das indústrias pré-colonial e proto-histórica da região. É necessário, porém, pesquisas em um maior número de sítios históricos da região, afim de se verificar se esta correlação entre alguns artefatos cerâmicos históricos e cauixi é restrita a desterminados contextos do sítio Aldeia, conforme sugerido pelas amostras das unidades 6 e 7 (não incluídas no presente estudo por serem majoritariamente pré-coloniais).

Com relação às louças dipped ware, Otto informa que essas tinham um apelo particular para populações tradicionais, como os agricultores africanos e os escravos afro-americanos ${ }^{94}$. De fato, louças apresentando esses padrões decorativos, predominantemente em formas côncavas, são comuns nos sítios de ocupação afro-americana dos Estados Unidos e Caribe ${ }^{95}$. Do mesmo modo, as louças cut sponge parecem ter tido um apelo similar para populações tradicionais. Cabak e Loring observam que essas louças são muito populares nos sítios de Labrador que foram ocupados pelos Invit durante a segunda metade do século XIX e início do XX. Eles notam ainda que, em um universo de mais de 500 sítios históricos ao longo do rio Savanna, sudoeste dos Estados Unidos, louças com essa decoração são extremamente raras, exceto no sítio Rancho Punta de Agua, em Tucson, Arizona, o qual foi ocupado por um grupo doméstico misto, de ascendência nativo-americana e européia ${ }^{96}$. Para o caso dos contextos brasileiros, os achados em uma senzala do Engenho Água Fria, em Chapada dos Guimarães (MT) também sugerem que populações tradicionais, neste caso escravos africanos, privilegiaram louças com esse tipo de decoração ${ }^{97}$.

Kearney lembra-nos que, em determinados contextos, os valores utilitário e econômico de certos artefatos são sobrepujados pelo valor de signo
92. Ver Cascudo (1983, p. 104).

93. Ver Souza (2010)

94. Ver Otto (1984, p. 65).

95. Ver Moore (1985), Otto (1984) e Wilkie (2000).

96.Ver Cabak e Loring (2000, p. 23).

97. Ver Symanski (2006, p. 229). 
98.Ver Kearney (1996,p. 158).

99. Idem, p. 168-169. atribuído aos mesmos, o que torna tais objetos elementos ativos na afirmação de identidades ${ }^{98}$. Segundo ele, tais signos saturados de valores, quando consumidos, nutrem a identidade de classe do agente consumidor, o qual, deste modo, consome valor como uma estratégia de resistência ${ }^{99}$. Este pode ter sido o caso das louças dipped ware e cut sponge da unidade 4. Por terem um maior apelo estético para as populações tradicionais, é provável que ocupantes indígenas e mestiços dessa unidade tenham privilegiado essas louças em detrimento daquelas favorecidas pelos luso-brasileiros, como as decalcadas, que expressavam uma estética e valores europeu-ocidentais. Essas louças, portanto, talvez representem uma visão de mundo mestiça dos ocupantes da unidade 4, o que poderia ser esperado em uma unidade doméstica mista, de um homem português ou lusobrasileiro casado com uma mulher indígena. Desse modo, ao optarem por louças assim decoradas, que eram utilizadas no consumo de alimentos preparados em vasilhames cerâmicos de influência indígena, esses indivíduos poderiam estar realçando valores diferentes daqueles expressos pela visão de mundo dos colonizadores.

\section{Considerações finais}

Conforme discutido neste artigo, a cultura material doméstica de Santarém informa, por um lado, sobre os domínios de conflito e da diferença e, por outro, sobre os domínios ambíguos, das misturas de práticas e mestiçagens, entre os diversos grupos sociais que ocuparam esses espaços. Nesse sentido, as louças de chá apresentaram-se como as mais socialmente visíveis desses espaços domésticos, sendo os itens materiais europeus de maior valor econômico. Por outro lado, o preparo dos alimentos, uma prática caracteristicamente associada às mulheres, porém relacionada à esfera do trabalho doméstico, apresentou-se como um dos domínios menos socialmente visíveis, representado pelos vasilhames cerâmicos acordelados de produção local.

As diferenças também se fazem presente entre as unidades domésticas localizadas na área da elite (unidades 2 e 8), a praça Rodrigues dos Santos, e aquela mais periférica (unidade 4), dado que os ocupantes das primeiras tiveram uma maior preocupação com o investimento em itens de maior valor econômico como porcelanas, faianças finas européias decalcadas, louças para chá, e peças para servir alimentos, ao passo que os ocupantes da última privilegiaram as louças brancas e minimamente decoradas, com uma grande proporção de peças côncavas e com poucas peças para o consumo do chá. Estes ainda privilegiaram as louças decoradas em faixas (dipped ware banded) e estampadas em padrões seqüenciais (cut sponge), fazendo um menor uso daquelas decalcadas. Assim, os grupos domésticos dessas duas áreas de Santarém parecem ter manipulado a cultura material visando expressar diferentes valores e identidades, vinculados, por 
um lado, com uma elite luso-brasileira, e por outro, com um grupo mais aparentemente calcado em referenciais indígenas e mestiços.

A ambigüidade das misturas, contudo, é uma feição onipresente no conjunto material dessas unidades domésticas. Essa ambigüidade é particularmente notável na grande popularidade das louças côncavas, associadas ao consumo de ensopados, em todos os contextos, as quais parecem ter sido indiscriminadamente utilizadas por brancos, mestiços e índios, patrões e empregados, homens e mulheres, em uma fusão, conduzida pelas cozinheiras indígenas e mestiças, entre as tradições culinárias indígenas e portuguesas. Do mesmo modo, essa população não só consumiu faianças portuguesas e mais tarde louças européias, itens de vidro e de ferro, artefatos que atestam a inserção do capitalismo internacional, mas também produziu novos artefatos, que foram produto das trocas entre indígenas, portugueses, e, em uma menor escala, africanos. Este foi, particularmente, o caso da cerâmica utilitária acordelada, usada para processar e cozinhar alimentos, igualmente disseminada nas unidades domésticas analisadas, apesar das distinções de status verificadas a partir das louças. Quanto aos cachimbos cerâmicos, sobretudo aqueles que possuem uma iconografia barroca, também simbolizam os contatos interculturais que resultaram em inovações tecnológicas. Assim sendo, ao lado da reapropriação e valoração de certos padrões decorativos europeus presentes nas louças, a cerâmica constituiu o espaço de renegociação destas identidades contrastantes e ambíguas em Santarém.

A cultura material histórica remete, portanto, a um processo de contatos culturais e fusão de identidades ocorrido na cidade de Santarém, durante os séculos XVIII e XIX, que pode ser mais bem traduzido pelo termo mestiçagem. Esta nos parece uma abordagem que, ao relativizar a vitimização das populações indígenas e africanas em solo americano, confere a estas populações uma posição ativa em face ao poder colonial. De forma contrastante aos séculos XVI e XVII, que consiste em uma época de domínio, conquista do território e submissão das populações indígenas, o período subseqüente representa um esforço de estreita convivência entre diferentes grupos. É no espaço urbano em formação que estes encontros se dão de uma forma mais intensa e regular. Embora a segregação espacial entre portugueses e indígenas remanescentes das missões se mantenha em Santarém ainda no século XIX, as unidades domésticas habitadas por portugueses, índios e mestiços, possuem artefatos que não deixam dúvidas sobre a mescla cultural e material entre esses grupos.

\section{REFERÊNCIAS}

ACUÑA, Critóbal. de. Novo descobrimento do Grande Rio das Amazonas. In: LEITÃO, C. M. (trad.); Rojas, Carvajal E Acuña. Descobrimentos do Rio das Amazonas. São Paulo: Companhia Editora Nacional, 1941.p. 12-294.

Annals of Museu Paulista. v. 20. n.2. July.-Dec. 2012. 
AGOSTINI, Camilla. Resistência cultural e reconstrução de identidades: um olhar sobre a cultura material de escravos do século XIX. Revista de História Regional, Maringá, v. 3, n. 2, p. 115-137, 1998.

APPADURAI, Arjun. Gastro-Politics in Hindu South Asia. American Ethnologist, Arlington, v. 8, n.. 3, p. 494-511, ago. 1981.

AZEVEDO, Aluísio. O mulato (1881). Disponível em http://www.ebooksbrasil.org/adobeebook/ omulato.pdf

BAENA, Antônio Ladislau Monteiro. Ensaio corográfico sobre a Província do Pará. Brasília: Edições do Senado Federal, 2004 [1839].

BARATA, Frederico.A arte oleira dos Tapajó II. Os cachimbos de Santarém. Revista do Museu Paulista, São Paulo, nova série, n. 5, p. 183-98, 1951.

BARBOSA, Rosana. Um panorama histórico da imigração portuguesa para o Brasil. Arquipélago História, Ponta Delgada, 2a série, n. 7, p. 173-196, 2003.

BARRETO, Mauro Vianna. O Romance da Vida amazônica: uma leitura socioantropológica da obra literária de Inglês de Sousa. Presidente Venceslau: Letras à Margem, 2003.

BATES, Henry Walter. O naturalista no Rio das Amazonas. São Paulo: Companhia Editora Nacional, $1944.2 \mathrm{v}$.

Um naturalista no Rio Amazonas, São Paulo: Editora da Universidade de São Paulo, Livraria Itatiaia Editora Ltda, 1979.

BETENDORF, João Felippe. Chronica da missão dos padres da Companhia de Jesus no Estado do Maranhão. Revista do Instituto Histórico e Geográfico Brasileiro, Rio de Janeiro, Tomo 72, Parte I, 1909.

BROCHADO, José Proenza. Contatos entre europeus e indígenas: um estudo de aculturação através das mudanças na cultura material. Revista do IFCH, Porto Alegre, n. 2, p. 11-47, 1974.

CABAK, Melanie; LORING, Stephen. "A Set of Very Fair Cups and Saucers": Stamped Ceramics as an Example of Inuit Incorporation. International Journal of Historical Archaeology, Albany, v. 4, n. 1, p. 1-34, 2000.

CASCUDO, Luís da Camara. História da alimentação no Brasil, $2^{\mathrm{a}}$ edição. Belo Horizonte: Itatiaia, $1983.2 \mathrm{v}$.

História da alimentação no Brasil, $3^{\text {a }}$ edição.. São Paulo: Editora Global, 2004. 2 v.

CARVAJAL, Gaspar de. Relação do novo descobrimento do famoso Rio Grande que descobriu por grande ventura o Capitão Francisco de Orellana. Tradução por C. de Mello Leitão. In: LEITÃO, C. M. (Ed.), Rojas, Carvajal \& Acunã. Descobrimentos do Rio das Amazonas. São Paulo: Companhia Editora Nacional, 1941.p. 11-79.

CUSICK, James Gregory. Historiography of Acculturation: an evaluation of concepts and their application in archaeology. In (Ed.) Studies in Culture Contact - interaction, culture change, and archaeology. Carbondale: Center for Archaeological Investigations, 1998, p. 126-145. 
DANIEL, João. Tesouro descoberto no máximo Rio Amazonas. Rio de Janeiro: Contraponto, 2004.2 v.

DEAGAN, Kathleen. Colonial Origins and Colonial Transformations in Spanish America. Historical Archaeology, Rockville, v. 37, n. 4, p. 3-13, 2003.

DELLE, James A. The Material and Cognitive Dimensions of Creolization in Nineteenth-century Jamaica. Historical Archaeology, Rockville, vol. 34, n. 3, p. 56-72, 2000.

FERGUSON, Leland. Uncommon Ground: archaeology and early African America, 1650-1800. Washington and London: Smithsonian Institution Press, 1992.

FLANDRIN, Jean-Louis.A alimentação camponesa na economia de subsistência. In: ; MONTANARI, Massimo. (Eds.). História da alimentação.Tradução por Luciano Vieira Machado e Guilherme João de Freitas Teixeira. São Paulo: Editora Estação Liberdade 1998. p. 580-610

FLORENCE, Hercule. Viagem do Tietê ao Amazonas. São Paulo, Edições Alumbramento, 1988

Viagem fluvial do Tietê ao Amazonas de 1825 a 1829.Tradução por Francisco Álvares Machado e Vasconcellos Florence. São Paulo: Museu de Arte de São Paulo Assis Chateaubriad, 1977.

FLORENTINO, Manolo; MACHADO, Cacilda. Ensaio sobre a imigração portuguesa e os padrões de miscigenação no Brasil (séculos XIX e XX). Disponível em: <http://www.ppghis.ifcs.ufrj.br/ media/manolo_imigracao_lusa.pdf>.Acesso em 10/01/2011.

FONSECA, Wilde Dias. Santarém: momentos históricos. Santarém: ICBS - Instituto Cultural Boanerges Sena/Prefeitura Municipal de Santarém, 2006. $5^{\mathrm{a}}$ ed.

FREYRE, Gilberto. Sobrados e mucambos. São Paulo: Global Editora, 2004. $15^{\text {a }}$ edição.

GOMES, Denise Maria Cavalcante. Cerâmica arqueológica da Amazônia: vasilhas da coleção Tapajônica do MAE-USP. São Paulo: Edusp/Fapesp /Imprensa Oficial, 2002.

Identificação de sítios arqueológicos da cultura Santarém na área central da Cidade de Santarém, PA. Relatório Final Apresentado ao IPHAN, 2006. Inédito.

Relatório da etapa de campo relativa à escavação do Sítio Aldeia - Santarém, PA. Projeto de Pós-Doutorado: Cronologia e contexto cerimonial da cultura Santarém. Relatório Parcial apresentado ao IPHAN, 2008. Inédito.

Relatório parcial do Projeto "Análise das Sócio-cosmologias amazônicas pré-coloniais" apresentado à FAPESP, 2010. Inédito.

GOSDEN, Chris. Post-colonial Archaeology: issues of culture, identity, and knowledge. In: HODDER, Ian. (Ed.). Archaeological theory today. Malden: Blackwell Publishers, 2001. p. 241-261.

Archaeology and Colonialism: cultural contact from 5000 BC to the present. Cambridge: Cambridge University Press, 2004.

GROOVER, Mark D. Evidence for Folkways and Cultural Exchange in the 18th Century South Carolina Backcountry. Historical Archaeology, Rockville, v. 28, n. 1, p. 41-64, 1994.

GRUZINSKI, Serge. O pensamento mestiço.Tradução por Rosa Freire d’́Aguiar. São Paulo: Companhia das Letras, 2001. 
GUAPINDAIA, Vera Lúcia Calandrini. L. C. Fontes históricas e arqueológicas sobre os Tapajó: a coleção Frederico Barata do Museu Paraense Emílio Goeldi, Recife, Universidade Federal de Pernambuco, Dissertação de Mestrado, 1993.

HERIARTE, Mauricio de. Descriçam do Estado do Maranham, Para, Corupa, Rio das Amazonas. Viena: Carlos Gerold, 1874.

HILL, Jonathan D.Violent Enconters: ethnogenesis and ethnocide in long term contact situations. In: CUSICK, James G. (Ed.). Studies in Culture Contact - interaction, culture change, and archaeology. Carbondale: Center for Archaeological Investigations, 1998. p.146-171.

HOWSON, Jean. Social Relations and Material Culture: a critique of the archaeology of plantation slavery. Historical Archaeology, Rockville, v. 34, n. 2, p. 78-91, 1990.

KEARNEY, Michael. Reconceptualizing the Peasantry:Antbropology in global perspective. Boulder:Westview Press, 1996.

KIDDER, Daniel Parish. O Brasil e os brasileiros. Tradução por Elias Dolianiti. São Paulo: Companhia Editora Nacional, 1941.

LIMA, Tania Andrade. Chá e simpatia: uma estratégia de gênero no Rio de Janeiro oitocentista. Anais do Museu Palista: História e Cultura Material, São Paulo, n. 3, p. 93-129, 1997.

. El huevo de la serpiente: una arqueología del capitalismo embrionário en el Rio de Janeiro del siglo XIX. In: ZARANKIN,Andrés;ACUTO, Félix. (Eds.). Sed Non Satiata - teorial social en la arqueología latinoamericana. Buenos Aires: Ediciones del Tridente, 1999. p. 189-238.

MILLER, George L. Classification and Economic Scaling of 19 th. Century Ceramics. Historical Archaeology, Rockville, n. 14, p.1-40, 1980.

A Revised Set of CC Index Values for Classification and Economic Scaling of

English Ceramics from 1787 to 1880. Historical Archaeology, Rockville, v. 25 n. 1, p. 1-25, 1990.

MOORE, Sue Mullins. Social and Economic Status on the Coastal Plantation: an archaeological perspective. In: SINGLETON,Theresa. (Ed.). The Archaeology of Slavery and Plantation Life. San Diego:Academic Press, 1985. p.141-160.

MORALES Walter Fagundes. A escravidão esquecida: a administração indígena em Jundiaí durante o século XVIII. Dissertação (Mestrado), Faculdade de Filosofia, Letras e Ciências Humanas, Universidade de São Paulo, São Paulo, 2000.

NIMUENDAJU, Curt. Os Tapajó. Boletim do Museu Paraense Emílio Goeldi, Belém, n.10, p. 93$106,1948$.

In Pursuit of an Amazonian Past:Archaeological researches in the Brazilian Guyana in the Amazon Region. Etnologiska Studier, Goteborg, n. 45, 2004.

OLIVEIRA, Adélia Engracia de. Amazônia: Modificações sociais e culturais. Boletim do Museu Paraense Emílio Goeldi, Série Antropologia, Belém, v. 4, n. 1, p. 65-115, 1988.

OTTO, John Solomon. Cannon's Point Plantation - 1794-1860 - Living conditions and status patterns in the Old South. Orlando:Academic Press, 1984. 
PORRO, Antônio. O povo das águas: Ensaios de etno-história amazônica. Petrópolis: Vozes-Edusp, 1996.

QUEIROZ, Maria Izaura Pereira de. Cultura, Sociedade rural e sociedade urbana no Brasil. Rio de Janeiro: Livros Técnicos e Científicos Editora S/A; São Paulo: Edusp, 1978.

QUINN, Ellen R. Excavating "Tapajó" Ceramics at Santarém: their age and archaeological context.Tese (Doutorado), University of Illinois at Chicago, Chicago, 2004.

REIS FILHO, Nestor Goulart. Quadro da arquitetura no Brasil. São Paulo: Editora Perspectiva, 1995.

ROOSEVELT, Anna C. Determinismo Ecológico na Interpretação do Desenvolvimento Social Indígena da Amazônia. In: NEVES, Walter. (Ed.) Adaptações e diversidade do bomem nativo da Amazônia, Belém: Museu Paraense Emílio Goeldi, pp. 103-142, 1991.

.Arqueologia amazônica. In: CUNHA, Manuela Carneiro da (Ed.), História dos índios do Brasil, São Paulo: Companhia das Letras, pp. 53-86, 1992.

Complex Polities in the Ancient Tropical World.Archaeological Papers of the American Anthropological Association, 9, p. 13-33, 1999.

.A Historical Memoir of Archaeogical Research in Brazil (1981-2007). Boletim do Museu Paraense Emílio Goeldi, Belém, 4 (1), p. 155-170, 2009.

SAMPAIO,Alberto José de. A alimentação sertaneja e do interior da Amazônia. São Paulo: Companhia Editora Nacional, 1944.

SHANKS, Michael. Culture/Archaeology: the dispersion of a discipline and its objects. In: HODDER, Ian. (Ed.). Archaeological Theory Today. Malden: Blackwell Publishers, 2001. p. 284-305.

SINGLETON, Theresa. Cultural Interaction and African-American Identity in Plantation Archaeology. In: CUSICK, James Gregory. (Ed.). Studies in Culture Contact - interaction, culture change, and archaeology. Carbondale: Center for Archaeological Investigations, 1998. p.172-189.

SMITH, Monica L. The Archaeology of Food Preference. American Antbropologist, Arlington, v. 108, n. 3, p. 480-493, 2006.

SOUZA, Marcos André Torres de. Entre práticas e discursos: a construção social do espaço no contexto de Goiás do século XVIII. In: ZARANKIN, Andrés.; SENATORE, Maria Ximena. (Eds.). Arqueologia da sociedade moderna na América do Sul - cultura material, discursos e práticas. Buenos Aires: Ediciones del Tridente, 2002. p. 63-86.

. Divisões sociais, utensílios cerâmicos e o preparo da farinha de mandioca no Brasil colonial. Clio - Série Arqueológica, Recife, v. 25, p. 97-127, $2010 .$.

SPIX, Johann Baptiste von; MARTIUS, Carl Friedrich Philipp von. Viagem pelo Brasil 1817-1820. Belo Horizonte: Itatiaia; São Paulo: Editora da Universidade de São Paulo, 1981.

STEIN, Gil J. Introduction: the comparative archaeology of colonial encounters. In (Ed.). The Archaeology of Colonial Encounters - comparative perspectives. Santa Fe: School of American Research Press, 2005. p. 3-32. 
SYMANSKI, Luís Claudio Pereira. Espaço privado e vida material em Porto Alegre no século XIX. Porto Alegre: Edipucrs, 1998.

Louças e auto-expressão em regiões centrais, adjacentes e periféricas do Brasil. In: ZARANKIN,Andrés; SENATORE, Maria Ximena. (Eds.). Arqueologia da sociedade moderna na América do Sul - cultura material, discursos e práticas. Buenos Aires: Ediciones del Tridente, 2002. p. 31-62

Slaves and planters in Western Brazil:material culture, identity and power. Tese (Doutorado), Department of Anthropology, University of Florida, Gainesville, 2006.

SYMANSKI, Luís Claudio Prereira; SOUZA, M.A.T. O registro arqueológico dos grupos escravos: questões de visibilidade e preservação. Revista do Patrimônio Histórico e Artístico Nacional, Rio de Janeiro, n. 33, p. 215-244, 2007.

TAVARES, Rufino Luis. O Rio Tapajoz. Rio de Janeiro:Typhographia Nacional, 1876.

TOCCHETTO, Fernanda. Joga lá nos fundos!: sobre práticas de descarte de lixo doméstico na Porto Alegre oitocentista. Arqueología Suramericana, Cauca, .1, n. 1, p. 49-75, 2005.

WHEATON, Thomas R.; GARROW, Patrick H.Acculturation and the Archaeological Record in the Carolina Low Country. In: SINGLETON,Theresa A. (Ed.). The Archaeology of Plantation and Slave Life. Orlando:Academic Press, 1985. p. 239-259.

WILKIE, Laurie A. Culture Bought: evidence of creolization in the consumer goods of an enslaved Bahamian family. Historical Archaeology, Rockville, v. 34, n. 3, p.10-26, 2000.

ZANETINNI, Paulo Eduardo. Maloqueiros e seus palácios de barro: o cotidiano doméstico na casa bandeirista.Tese (doutorado), Universidade de São Paulo, São Paulo, 2005. 